\title{
LA FIABILIDAD EN LA DISTRIBUCIÓN GEOGRÁFICA DE LAS EXPORTACIONES ARGENTINAS, 1875-1913
}

\section{RELIABILITY IN THE GEOGRAPHICAL DISTRIBUTION OF ARGENTINE EXPORTS, 1875-1913}

\author{
Anna Carreras-Marín \\ Universitat de Barcelona, Barcelona, España, annacarrerasmarin@ub.edu* \\ Agustina Rayes \\ Universidad Nacional del Centro de la Provincia de Buenos Aires, Buenos Aires, Argentina, \\ agusrayes@hotmail.com**
}

Resumen. El desempeño de la exportación en América Latina durante la primera globalización ha sido un tema muy estudiado en la historiografía. Sin embargo, la calidad de las fuentes de información para su análisis no ha sido tratada con la misma profundidad. En los últimos años han proliferado debates acerca de la fiabilidad de las estadísticas para conocer el crecimiento, la composición y la distribución geográfica del comercio exterior de la región. En este artículo proponemos confrontar los resultados de una nueva serie -reconstruida a precios de plaza de Buenos Aires y corregida en su asignación con las exportaciones "a órdenes"- con los registros de los principales socios comerciales de Argentina entre 1875 y 1913. De esta forma, comparamos la fiabilidad de los datos corregidos con los oficiales, los cuales han sido mayoritariamente utilizados por la historiografía de forma acrítica.

Palabras clave: Argentina; exportaciones; fiabilidad estadística; asignación geográfica; primera globalización.

Abstract. Latin American exports during First Globalisation have long been a central topic in the literature of the region. In recent years, debates have focused the statistical accuracy of Latin American trade data in order to know better exports growth, their composition and geographical distribution. In this paper, we propose to compare a new data set -corrected by Buenos Aires' values and assigned with exports "for orders"with main trade partners' data between 1875 and 1913. Thus, we collate the accuracy of

* Agradezco el financiamiento recibido de la Red de Investigación XREPP, del proyecto de investigación ECO2012-39169-C03-03 financiado por el Ministerio de Innovación y Ciencia de España, así como el del grupo de investigación que cuenta con el soporte del Gobierno de Cataluña 2014SGR1345 (Centro de Investigación Antoni de Campany).

** Agradezco el financiamiento otorgado por el Consejo Nacional de Investigaciones Científicas y Técnicas de Argentina a través de una beca doctoral para llevar adelante esta investigación.

Am. Lat. Hist. Econ., año 22, núm. 3, septiembre-diciembre, 2015, pp. 177-212 
our corrected series compared to the official figures, which has been broadly used by historiography regardless its lack of accuracy.

Key words: Argentina; exports; statistical accuracy; geographical assignment; first globalisation.

Fecha de recepción: 14 de octubre de 2014. Fecha de aceptación: 06 de marzo de 2015

\section{INTRODUCCIÓN}

$\mathrm{D}$ urante la llamada Primera Globalización, periodo que se extiende entre las últimas décadas del siglo XIX y la primera guerra mundial, el caso argentino ha sido muy estudiado como ejemplo de export-led-growth. En este artículo no buscamos analizar la relación entre el crecimiento económico y las exportaciones, pues esa es una cuestión que abordamos en otros trabajos (Rayes, 2015a; 2015b). Nuestra propuesta consiste en contrastar la nueva evidencia empírica acerca de la distribución geográfica con los datos oficiales a partir de la comparación con la información procedente de los principales socios comerciales.

El ejercicio propuesto adquiere relevancia porque importantes estudios de la historiografía económica argentina e internacional, aunque en algunos casos reconocieron la problemática confiabilidad de los datos oficiales de Argentina, los utilizaron o presentaron sin corregir y sobre ellos construyeron sus aportaciones analíticas acerca del papel económico del comercio exterior en el país (Bértola y Gerchunoff, 2011; Bértola y Ocampo, 2013; Díaz, 1983; Gerchunoff y Llach, 2007; Mitchell, 1998; Rapoport, 2013; Vázquez, 1971, entre otros).

Pese al uso generalizado de los datos oficiales sin revisión, existieron esfuerzos de corrección como la labor realizada por el jefe de la Dirección General de Estadística de la Nación, Alejandro Bunge (1918), para la etapa 1910-1916. No obstante, la investigación más extendida en el tiempo fue la de Cortés Conde, Halperin Dongui y Gorostegui de Torres (1965), quienes corrigieron los valores oficiales cuando no representaban los precios de mercado con valores de exportación de plaza de Buenos Aires. Este trabajo, que fue escasamente utilizado por la historiografía por cuanto no fue publicado, significó la creación de una nueva serie de montos agregados y de composición de la canasta entre 1864 y 1963, pero no cubrió la asignación geográfica de las exportaciones, aspecto que nosotros abordamos en el presente trabajo. Recientemente, Tena y Willebald (2013) publicaron un significativo estudio de revisión de las estadísticas argentinas en el que corrigieron las series al sustituir los valores nominales argentinos por los del mercado de Londres, a la vez que introdujeron una estimación del comercio "a ór- 
denes" según los resultados de las exportaciones directas. Así, estos autores aportaron nueva evidencia en favor de la tradicional hipótesis de infravaloración de la exportación argentina, lo que les ha permitido revisar el alza en la evolución exportadora argentina durante la primera globalización.

Nosotros corregimos la distribución de la exportación argentina al seguir los precios de plaza de Buenos Aires, tal como planteara la investigación de Cortés, Halperin y Gorostegui de Torres (1965) para la composición de la canasta, y hemos resuelto el problema de las exportaciones "a órdenes" con un nuevo criterio utilizando fuentes contemporáneas. Nuestro trabajo se enmarca en una reciente línea de investigación que ha puesto de relieve la aceptable validez de las estadísticas oficiales de América Latina en general (Carreras-Marín y Badia-Miró, 2008; Carreras y Tafunell, 2005; Kuntz, 2002; Rubio y Folchi, 2005, entre otros), frente a los estudios que en el pasado negaron totalmente su fiabilidad (Allen y Elly, 1953; Morgernstern, 1963; Platt, 1971) al reconstruir el desempeño de la región en los escenarios internacionales a partir de los datos procedentes casi exclusivamente de Estados Unidos y Gran Bretaña. Al ser identificado el caso argentino en la literatura internacional como un caso de inexactitud estadística en su comercio exterior, el trabajo tiene interés tanto para los debates historiográficos locales como para un debate más general de la fiabilidad de las estadísticas históricas de comercio exterior. La principal diferencia del presente trabajo en relación con el de Tena y Willebald (2013) radica en que mientras estos últimos se centran especialmente en el análisis de los ritmos de crecimiento de las exportaciones que arroja su nueva serie de datos corregida, nuestra atención se orienta hacia el análisis de la distribución geográfica de las series oficiales, frente a las nuevas series corregidas, disponibles en términos bilaterales.

El artículo inicia con una reseña acerca del debate general sobre la fiabilidad y la comparabilidad de las estadísticas oficiales de comercio exterior. Después, se examinan los alcances y limitaciones de las principales obras estadísticas sobre las exportaciones argentinas entre 1875 y 1913; continúa con una explicación metodológica sucinta acerca de la serie de exportación argentina que aquí se propone contrastar junto a la serie de valores oficiales, y realiza un ejercicio de contraste de los resultados de los datos oficiales y la nueva serie con los registros de importación de los principales socios (Reino Unido, Alemania, Francia, Bélgica, Estados Unidos, Italia, España y Brasil), utilizando el índice de Morgernstern (1963) en términos bilaterales. Decidimos comparar nuestros resultados con la serie oficial porque es la que se ha utilizado extensamente en la literatura previa y porque, a excepción del trabajo de Tena y Willebald (2013), ninguna otra ha ofrecido una reconstrucción sistemática de la distribución geográfica de las exportaciones. Finalmente, se evalúa el aporte en el conocimiento de la 
asignación geográfica de la nueva serie en relación con los datos oficiales sin correcciones.

\section{EL DEBATE INTERNACIONAL SOBRE LA FIABILIDAD DE LAS ESTADÍSTICAS HISTÓRICAS DE COMERCIO EXTERIOR}

\section{La distribución geográfica en el centro de la cuestión}

La fiabilidad de las estadísticas de comercio exterior es una problemática que va más allá del caso de Argentina. Existe una extensa literatura sobre el tema, desde las investigaciones de Allen y Elly (1953) y Morgernstern (1963) hasta las aportaciones de Federico y Tena (1991) y Tena (1991, 1992).

Los primeros trabajos basados en la comparación de las series de exportación e importación de distintos países se caracterizaron por un cierto grado de pesimismo. No obstante, la valoración negativa se ha ido suavizando paulatinamente, en parte, a causa de la ausencia de fuentes estadísticas alternativas, pero también por la compensación de errores a través de la agregación geográfica y sectorial de los datos.

El cuestionamiento del uso de los datos oficiales surge por la idea de que la exportación de un país $(\mathrm{X} i j)$ es simultáneamente la importación de su socio comercial $(\mathrm{M} i j)$. De este modo, por definición, los datos del país exportador deben coincidir con los del importador $(\mathrm{X} i j=\mathrm{M} i j)$. En la práctica, sin embargo, cuando se comparan ambos registros, casi nunca coinciden.

En 1953 se publicó una recopilación de estudios, realizada por Allen y Elly, que se encuentra en la base de la literatura posterior sobre la fiabilidad de las estadísticas oficiales de comercio exterior. En esta obra, Dana Durand (1953) identificaba las principales causas que pueden explicar las divergencias entre las estadísticas de los distintos países: $a$ ) cobertura y definición de las mercancías registradas; $b$ ) el nivel de detalle de cada método estadístico usado; $c$ ) los métodos para identificar la asignación geográfica, es decir, la procedencia de las importaciones y el destino de las exportaciones; d) los cálculos de valores, con o sin costes de transporte, con valores declarados u oficiales, o bien, con distintos tipos de cambio, y $e$ ) la incapacidad de los agentes comerciales (voluntaria o no) para dar información fiable.

Cada una de las causas presentadas sintéticamente en el anterior párrafo, responde a distintas situaciones. El uso de distintos criterios de clasificación de las mercancías $(a)$ o el nivel de detalle de las mismas $(b)$ se ha vinculado con la importancia de cada producto en la estructura comercial del país. En cuanto a los métodos de la asignación geográfica $(c)$, en el momento de determinar la procedencia de una importación se pueden seguir distintos criterios: el puerto precedente en una ruta marítima, el primer 
puerto del que parte un barco o el país en el que se produce originalmente la mercancía. Por otro lado, respecto al destino de la exportación se puede optar por asignarlo al primer o al último puerto de la ruta marítima, o al país donde finalmente se consume la mercancía transportada.

Otra causa de discrepancias en las estadísticas de dos socios comerciales son los criterios de valoración de las mercancías comercializadas $(d)$. En general, se supone que las exportaciones se valoran sin los costes de transporte ni otros, a excepción de aquellos gastos previos a dejar la mercadería en el puerto de salida, es decir, FOB (free on board), y las importaciones incluyen los fletes, seguros marítimos y comisiones mercantiles, es decir, se valoran en precios CIF (cost, insurance, freight) (Sutch y Carter, 2006; Organización Mundial del Comercio, 2011). Sin embargo, esta convención no ha sido seguida ni por todos los países ni en todos los años. Así, por ejemplo, las estadísticas oficiales chilenas en algunos periodos ofrecen tanto los datos de importación como los de exportación en valores FOB (Carreras-Marín, Badia-Miró y Peres-Cajías, 2013).

La última causa de las diferencias en las estadísticas oficiales se refiere a la capacidad de los agentes comerciales para dar información de forma precisa $(e)$. Estos errores pueden deberse a la ocultación voluntaria o a omisiones involuntarias. A ello se añade la problemática de las reexportaciones, de especial importancia para algunos países cuyos puertos no eran los consumidores finales de los artículos que arribaban, así como el contrabando que afectaba a las mercancías importadas sometidas a fuertes barreras de entrada. En el caso argentino, el comercio "a órdenes", que se explicará más adelante, es un caso de reexportación.

En el marco de la diversa naturaleza de las discrepancias estadísticas históricas entre socios comerciales, el trabajo de Morgernstern (1963) representa el primer intento de cuantificar su impacto. Para ello, utilizó un índice que ponderaba la diferencia entre dos países por el valor del comercio en uno de ellos. El índice de Morgernstern se ha aplicado a las exportaciones del siguiente modo: $\mathrm{I}_{i j}=\left(\mathrm{X}_{i j} / \mathrm{M}_{i j}\right)$ por 100 . Donde $\mathrm{I}_{i j}=$ índice de Morgernstern para la exportación del país $i$. $\mathrm{X}_{i j}=$ exportaciones del país $i$ al país $j$ en las estadísticas de $i$ (precios FOB). $\mathrm{M}_{i j}=$ exportaciones del país $i$ al país $j$ en las estadísticas de $j$ (precios CIF).

Morgernstern aplicó su índice a los años 1909-1913, 1928, 1935, 1938, 1948, 1952, 1956 y 1960. La muestra incluía a Estados Unidos, Canadá, Bélgica, Reino Unido, Alemania y Francia, para los que cabría esperar mejores resultados en términos de precisión estadística, si se cumple la premisa de que a mayor desarrollo económico, mayores recursos para la recolección de información y el tratamiento estadístico. A pesar de ello, los resultados fueron claramente negativos. La comparación entre series difería en más de $25 \%$ en la mayor parte de los casos. Dicho $25 \%$ se usa- 
ba como límite máximo atribuible a los posibles costes de transporte que podían estar incluidos en unas importaciones CIF y excluidos en unas exportaciones FOB. El único resultado positivo era que estas diferencias se reducían a medida que avanzaba el tiempo.

Pero el problema para Morgernstern no se encontraba sólo en los elevados porcentajes de las discrepancias. Una segunda causa para el pesimismo procedía de la arbitrariedad de los signos. Según el autor, el mayor problema era explicar los signos positivos, es decir, las situaciones en las que lo que declaraba el exportador superaba lo que el importador dice recibir. El contrabando podía ser una respuesta, pero las dificultades de su estimación suponían un problema adicional para validar la fiabilidad de las series.

Para Morgernstern, la arbitrariedad de los signos era el elemento que, sumado a los elevados porcentajes de las diferencias, determinaba la poca credibilidad de las estadísticas de comercio exterior. Sin embargo, Federico y Tena (1991) y Tena (1992) han rectificado las valoraciones más pesimistas de Morgernstern (1963), al concluir que, salvo algunas excepciones para países concretos, las estadísticas históricas oficiales del comercio exterior tienen un grado de fiabilidad aceptable. Para llegar a esta conclusión, los autores utilizaron un índice de comparabilidad diseñado expresamente para superar los problemas de la asignación geográfica de los datos. Dicho índice consiste en dividir el comercio total del país “ $i$ ”, según las estadísticas del país " $i$ ", entre la suma de los datos recogidos en las estadísticas de sus socios comerciales. La fórmula se expresa del siguiente modo: $\mathrm{T}_{i}=\left(\sum \mathrm{X}_{i j} / \sum \mathrm{M}_{i j}\right)$. Donde $\mathrm{T}_{i}$ es el índice de Federico y Tena para las exportaciones del país $i$. $\mathrm{X}_{i j}$ es la suma de la exportación del país $i$ hacia los socios comerciales $(j)$, según la estadística de $i . \mathrm{M}_{i j}$ es la suma de la importación de $j$ procedente de $i$, según la estadística de $j$.

Si la agregación de las exportaciones coincide con la suma de las importaciones de los socios comerciales, el índice toma el valor 1. CarrerasMarín (2005) y Carreras-Marín y Badia-Miró (2008) se han inscrito en la línea de los trabajos de Federico y Tena (1991), llevando la confiabilidad de las estadísticas al terreno de la distribución comercial bilateral para el caso de América Latina. La estimación de un modelo econométrico de las discrepancias estadísticas a través de la distancia y de la dimensión del flujo del comercio permitió a estos autores detectar la significación de estas variables para explicar los desajustes de los países de América Latina y sus principales socios comerciales. De esta manera, los autores no niegan la existencia de diferencias estadísticas entre los países de América Latina y sus socios comerciales, pero al ser capaces de identificar patrones explicativos de las mismas, validan su fiabilidad.

A partir de la literatura internacional sobre fiabilidad estadística reseñada en este apartado, nuestro trabajo consiste en aplicar los índices de 
comparabilidad de Morgenstern (1963) al comercio de Argentina y algunos de los principales socios comerciales para el periodo 1875-1913. Adicionalmente, usamos el índice de Federico y Tena (1991) de forma agregada para una muestra de países que recoge porcentajes muy significativos del comercio total de exportación argentino.

\section{LAS EXPORTACIONES DE ARgEnTINA 1875-1913}

\section{El debate sobre la fiabilidad de las distintas series}

La compilación de información estadística fue una preocupación de los distintos gobiernos desde la independencia del Río de La Plata, enfatizada aún más en la segunda mitad del siglo XIX cuando cristalizó el proceso de construcción del Estado nacional argentino. En el marco de estos esfuerzos estadísticos, desde 1864 se publicaron los Anuarios de la Dirección General de Estadística de la Nación (en adelante ADGEN). ${ }^{1}$ Las obras estadísticas dedicadas a las exportaciones argentinas están basadas en las fuentes oficiales argentinas. No obstante, es importante distinguir entre aquellas que han procesado los datos sin ninguna corrección y las que han introducido modificaciones a fin de mejorar su fiabilidad.

En el primer grupo de trabajos se encuentran los estudios de Vicente Vázquez Presedo $(1969,1971)$. Estas publicaciones han estado entre las más usadas, especialmente en la historiografía argentina. Sin embargo, Vázquez Presedo no corrigió los valores de los bienes vendidos al exterior ni estimó los destinos definitivos de los embarques "por órdenes". Tampoco las obras con información estadística más generales elaboradas en las últimas décadas han revisado los valores oficiales ni han distribuido las exportaciones "a órdenes". Entre ellas, cabe reconocer las compilaciones de Mitchell (1998), cuyo esfuerzo principal estriba en la base de largo plazo y la extensa cobertura geográfica de los países estudiados, así como en el detalle de otras variables más allá de las exportaciones. Este trabajo es ampliamente referenciado en la historiografía internacional, sin embargo, está probado que para el caso argentino ha recogido la información oficial sin ninguna crítica. Tampoco la obra dirigida por Ferreres (2010), dedicada a la construcción de la historia argentina en cifras y que involucra muchos más aspectos que las exportaciones, ha corregido los datos incluidos.

\footnotetext{
${ }^{1}$ Estas publicaciones recibieron diversos nombres al igual que las instituciones que las patrocinaron. Entre 1882 y 1892 la fuente se denominó Estadística del comercio y de la navegación de la República Argentina correspondiente al año... Publicación oficial. Desde 1893 el nuevo título fue Anuario del Departamento Nacional de Estadística correspondiente al año...
} 
Resulta particularmente llamativo que las obras más utilizadas no revisaran los precios oficiales de las exportaciones argentinas, por lo menos en el periodo anterior a la primera guerra mundial, puesto que los jefes de la Dirección General de Estadística de la Nación (Bunge, 1918; Latzina, 1905) hicieron hincapié en la existencia de casos de sobrevaloración y especialmente de infravaloración. Durante su gestión a partir de 1914, Alejandro Bunge procuró que "el estudio de la estadística anual del comercio exterior respondiera a los interrogantes que las circunstancias del intercambio universal plantearon a la Argentina, en concordancia con las necesidades políticas, administrativas y económicas de información" (Bunge, 1918, pp. 7-9). Para ello, no sólo cambió el método de estimación de los precios, sino que se propuso realizar una corrección retrospectiva de los mismos para el periodo 1910-1916. De los 203 artículos que figuraron entre las exportaciones argentinas, sólo 57 representaron 95\% del total, de modo que la rectificación se hizo para esta cantidad de bienes (en algunos años llegó a 61 productos).

Pese a que la historiografía continuó utilizando los datos oficiales sin corrección, debemos reconocer un esfuerzo pionero en su revisión. A comienzos de la década de 1960, un grupo de historiadores, compuesto por Roberto Cortés Conde, Tulio Halperin Donghi y Haydée Gorostegui de Torres, realizó una serie para el periodo 1864-1963 en la que presentaban el material estadístico édito sobre las exportaciones argentinas, integrándolo con fuentes inéditas, previa crítica y ordenación. Entre sus principales aportes, esta obra corrigió los precios de los bienes más importantes durante 1864-1916, lo cual implicó, por un lado, una nueva estimación sobre la participación relativa de cada uno de los artículos en la canasta agroexportadora y, por el otro, el nuevo cálculo de los montos totales anuales (Cortés, Halperin y Gorostegui de Torres, 1965). No obstante, este trabajo no ha tenido un impacto historiográfico paralelo al aporte brindado, probablemente porque la obra nunca fue publicada y, en consecuencia, fue escasamente utilizada (entre las excepciones figuran Cortés, 1974; Diéguez, 1972; Míguez, 2008, por ejemplo). Adicionalmente, como el interés no fueron las exportaciones per se, sino las transformaciones en la estructura productiva de Argentina, la obra no contempló la participación relativa de los destinos.

En nuestro trabajo seguimos la metodología de Cortés, Halperin y Gorostegui de Torres (1965) al aplicar a los distintos bienes exportados los precios de plaza de Buenos Aires, recogidos fundamentalmente de la Bolsa de Comercio o de la Bolsa de Cereales. Consideramos que estos precios son indicados por varias razones. En primer lugar, porque estamos reconstruyendo las exportaciones, que se cotizan a valores FOB, ya que tomar precios de otros países nos conduciría a devengar de los mismos los 
costos de transporte -fluctuantes para la época y con situaciones irregulares como el caso de muchos barcos que trasladaban pasajeros a Argentina y regresaban con carga-, así como los gastos de seguro y operaciones de importación. Segundo, los precios contabilizados son precios mayoristas de exportación, que por estar tomados en Buenos Aires ya reúnen los costos previos para colocar las mercaderías en el puerto, punto no menor si tomamos en cuenta la extensión del territorio en el que se producían los artículos. Tercero, por tratarse de bienes que no iban dirigidos sólo a un mercado en particular, consideramos que los valores mayoristas de plaza argentina capturan el resultado de las bajas y alzas de los diferentes mercados en los que competían. Por esta razón descartamos el uso de precios de una sola plaza externa por central que sea a la economía internacional como es la de Londres, ya que no necesariamente refleja los movimientos de valores de los bienes argentinos.

Además de corregir los valores de los productos comprados por cada socio, ${ }^{2}$ revisión que, como señalamos, no había sido aplicada ni en los estudios de Bunge (1918) ni en los de Cortés et al. (1965), distribuimos la categoría de embarques "a órdenes". Desde 1895 y hasta 1927, la estadística comercial de exportación argentina careció del conocimiento de los destinos definitivos por la práctica conocida con el nombre de exportaciones "a órdenes" o "por órdenes", lo cual significaba destinar un cargamento a determinados puertos próximos a mercados de consumo, para que desde allí, y de acuerdo con el estado de las plazas europeas al momento de su llegada, se redireccionara la exportación al destino final. Este método se aplicaba especialmente a materias primas de bajo valor unitario y expuestas fuertemente a las fluctuaciones en sus valores, como trigo, maíz, lino y rollizos de quebracho. En consecuencia, el ingreso definitivo quedaba establecido un tiempo después de salido el embarque y de terminadas las operaciones aduaneras correspondientes, base de la estadística oficial. Esta deficiencia en el registro de la información no es un detalle de menor importancia en tanto que afectó en algunos años puntuales a un tercio del valor total exportado.

Para realizar la distribución de las exportaciones "a órdenes" tomamos los datos obtenidos por Ricardo Pillado, jefe de la Dirección Comercial del Ministerio de Agricultura, quien en 1908 publicó un trabajo estadístico cuyo objetivo había sido conocer qué parte de este tipo de exportaciones había llegado a determinados destinos. Para ello comparó la documentación nacional de exportación con la de importación de los compradores

\footnotetext{
${ }^{2}$ Es decir, restar a cada destino el monto de cada artículo exportado y sumarlo una vez más con los nuevos precios por las cantidades declaradas -ello sólo es posible si se cuenta con el cruce anual de información de productos por países.
} 
en el quinquenio 1901-1905 y obtuvo resultados sobre el volumen de trigo, lino, maíz y rollizos de quebracho hacia cada destino -Reino Unido, Alemania, Bélgica, Países Bajos, Francia, Austria y otros (ADGEN, 1909, p. XXII). Estos datos fueron usados para realizar un ejercicio de distribución de los envíos "por órdenes" entre los destinos para la etapa 1895-1913. En otro trabajo (Rayes, 2013b) se han explicado las ventajas de adoptar esta metodología por sobre la que proponen Tena y Willebald (2013), que consiste en distribuir los embarques "a órdenes" por destinos en proporción a las exportaciones directas. Este método de asignación geográfica conlleva sobrevaluar a Francia, que fue un socio fluctuante y menor de la clase de productos enviados "por órdenes", y subvaluar a Alemania, que fue un gran comprador de los granos exportados con esta modalidad.

\section{LA NUEVA SERIE: AVANCES EN EL CONOCIMIENTO DE LA DISTRIBUCIÓN GEOGRÁFICA DE LAS EXPORTACIONES ARGENTINAS}

Con las correcciones realizadas para conocer la distribución geográfica es posible, por un lado, evaluar la fiabilidad de la nueva serie en relación con la información procedente de sus principales socios comerciales y, por el otro, contrastar estos resultados con los de la serie oficial. Para realizar el contraste, se han transformado los valores en las monedas convertibles de los distintos países a libras esterlinas. ${ }^{3}$ Finalmente se ha aplicado el índice de Morgenstern (1963) a los datos oficiales de Argentina sin correcciones (ADGEN) y a nuestra serie. La disponibilidad de datos no ha permitido realizar un análisis exhaustivo de todos los socios comerciales de Argentina, alcanzándose sin embargo porcentajes de representatividad razonablemente significativos, que oscilan para los distintos años del periodo entre un mínimo de 55 y un máximo de $88 \%$, con un valor medio de $72 \%$ y una desviación estándar de casi $9 \%$ (véase gráfica 1).

Los socios comerciales incluidos han sido Reino Unido, Estados Unidos, Francia, Alemania, Brasil, Italia, España y Bélgica. Esta muestra de países coincide en su mayor parte con la utilizada en el trabajo de Tena y Willebald (2013) con alguna excepción. En este caso hemos incluido también a Brasil, que fluctúa entre 2 y $13.5 \%$ de la exportación argentina, según nuestra serie. Por otro lado, Tena y Willebald incluyen los Países Bajos sólo para el periodo de 1905 a 1913. En este caso no hemos incluido

${ }^{3}$ La conversión de pesos oro argentinos a libras esterlinas se realizó tomando la investigación de Álvarez (1929). Los datos de tipo de cambio necesarios para la comparación de valores expresados en monedas corrientes de los países europeos considerados proceden del trabajo de Accominotti, Flandreau y Rezzik (2011). 


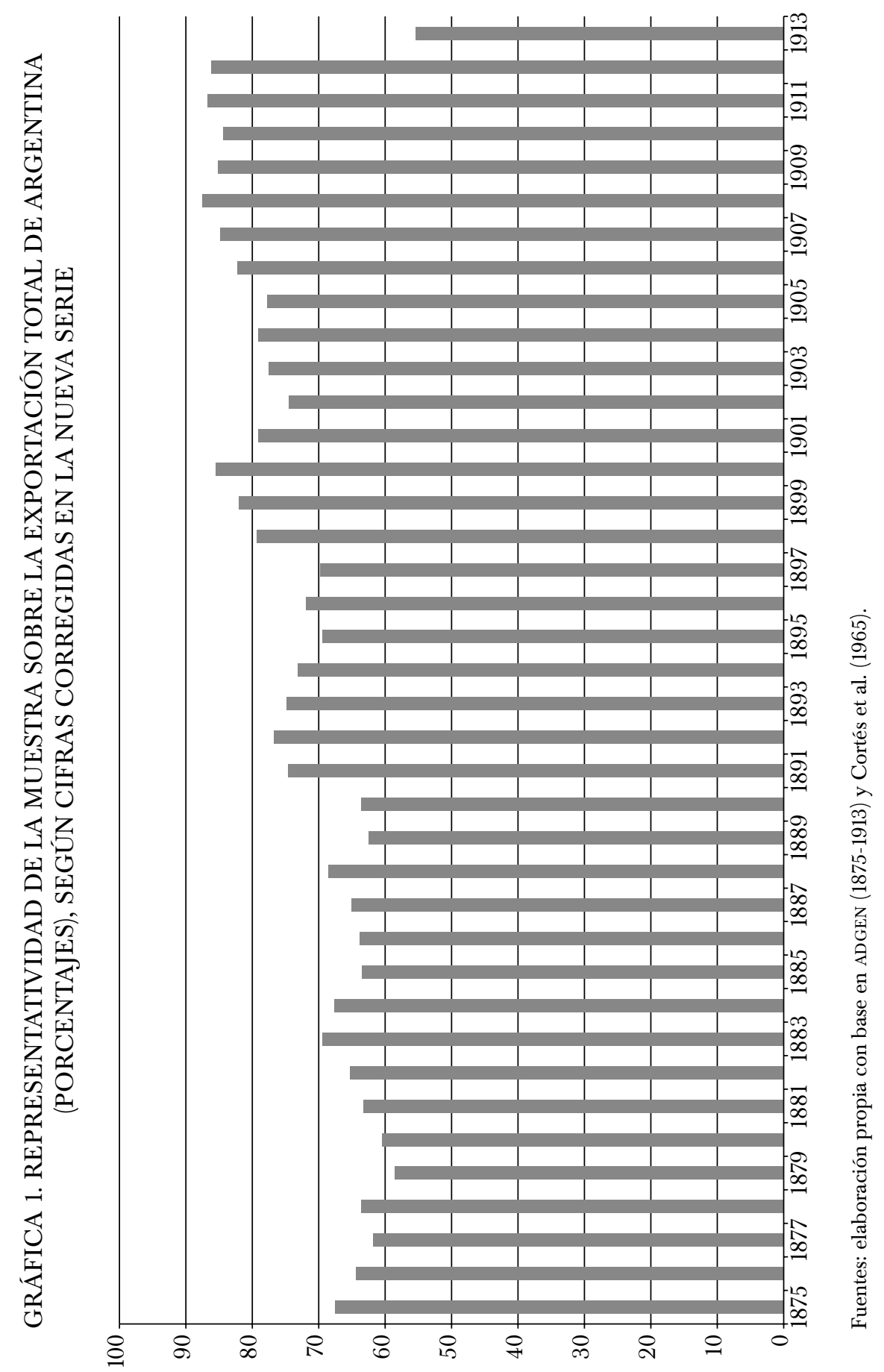


a este país debido a la reconocida problemática de reexportación en las estadísticas holandesas.

Aunque el periodo general comprende de 1875 a 1913, no ha sido posible cubrir todos los años para todos los países debido a problemas de disponibilidad de los datos de los socios comerciales. De esta forma, sólo en los casos del Reino Unido, Francia y España se abarca íntegramente el periodo, mientras que en el caso belga se cubre de 1875 a 1912, en el de Alemania la comparación se realiza para 1889-1912, en el caso de Brasil de 1901 a 1913, y en el de Italia entre 1890 y 1912. Con la excepción de Brasil, cuyas estadísticas empiezan en 1901, para el resto de los países se cubre un periodo suficientemente extenso.

La distribución geográfica de las exportaciones argentinas entre 1875 y 1913 atiende a los datos de la nueva serie corregida (véase gráfica 2). Se observa que los principales socios comerciales fueron Reino Unido, Francia, Bélgica y Alemania. Según estos datos, el peso del Reino Unido osciló entre 6 y 43\%, con un valor medio de 23\%, lo que determina que el análisis de la fiabilidad con este país sea muy relevante, especialmente para las últimas décadas del periodo. Es de destacar que estos porcentajes difieren de los presentados por la serie de Tena y Willebald (2013), según la cual el porcentaje máximo del Reino Unido se sitúa en 25\% y el mínimo en 10\%, calculados como medias quinquenales. Esta discrepancia en los resultados puede deberse a los distintos precios usados en ambas series, así como a los métodos también distintos de asignación geográfica del comercio "a órdenes". La diferencia que se reporta con Tena y Willebald responde, precisamente, a que la corrección de las series de exportaciones en el caso de los autores mencionados no se realiza de acuerdo con la distribución geográfica, sino que se ha llevado a cabo por la vía de los bienes. Es probable que la corrección que aquí se utiliza sea más adecuada para el caso de la distribución geográfica del comercio.

$\mathrm{El}$ análisis de la fiabilidad de las series argentinas en comparación con la estadística británica se hizo a partir de los resultados del índice de Morgenstern (1963) (véase gráfica 3). Cabe señalar que el signo esperado de esta comparación es negativo, debido a que los costes de transporte se suponen incluidos en las importaciones (dato procedente de la estadística británica), mientras que están exentos en las exportaciones (dato procedente de las estadísticas argentinas). En cuanto a la magnitud que razonablemente cabe esperar que tengan los costes de transporte de los precios CIF en la diferencia entre los datos de exportación e importación se pueden establecer distintos intervalos. Por un lado, en su tradicional trabajo, Morgenstern (1963) eligió arbitrariamente 25\% como límite máximo. Una estimación más rigurosa, que cuenta además con la ventaja de basarse en el caso de Argentina con sus socios comerciales, la ofrecen Tena y Wille- 


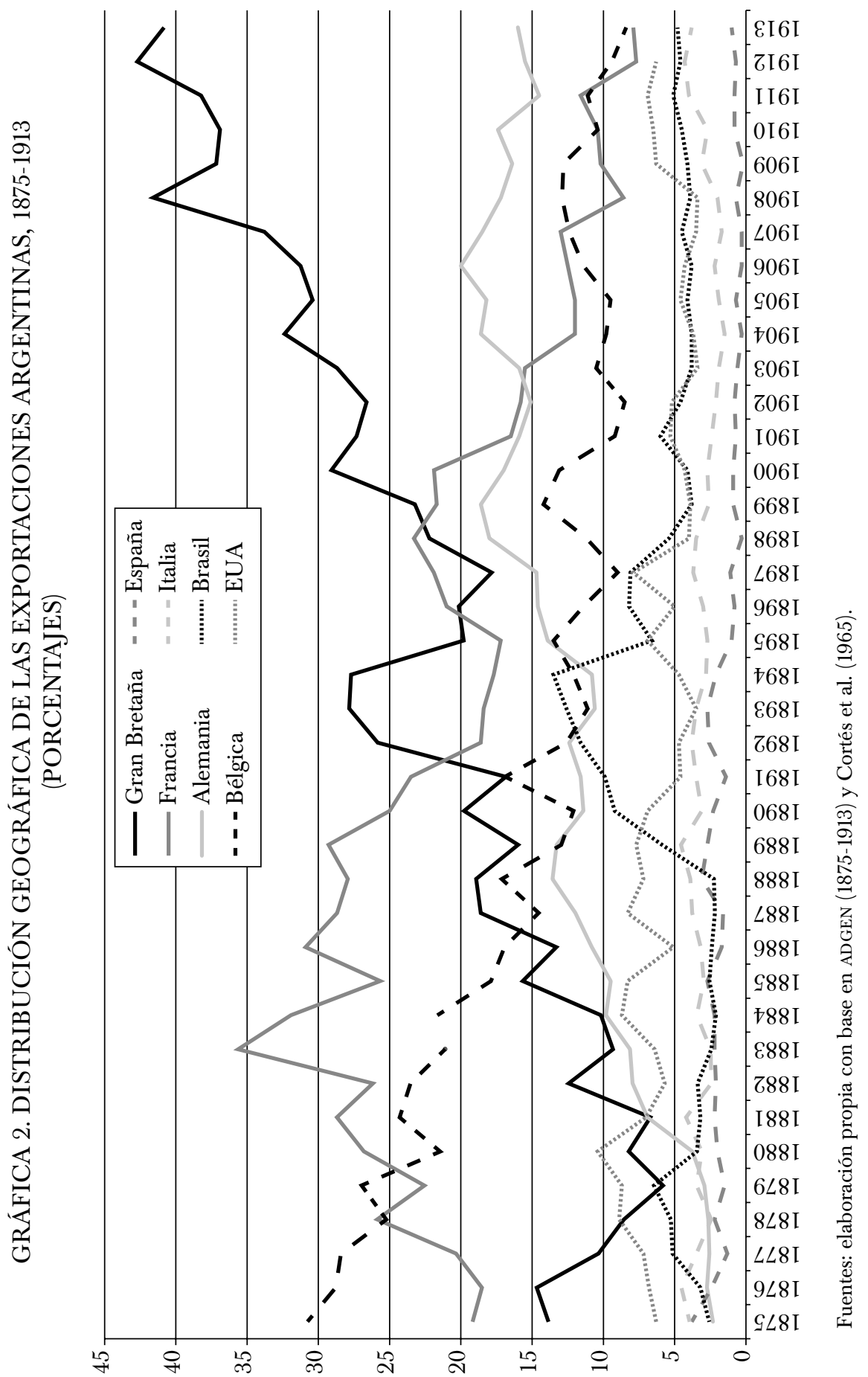




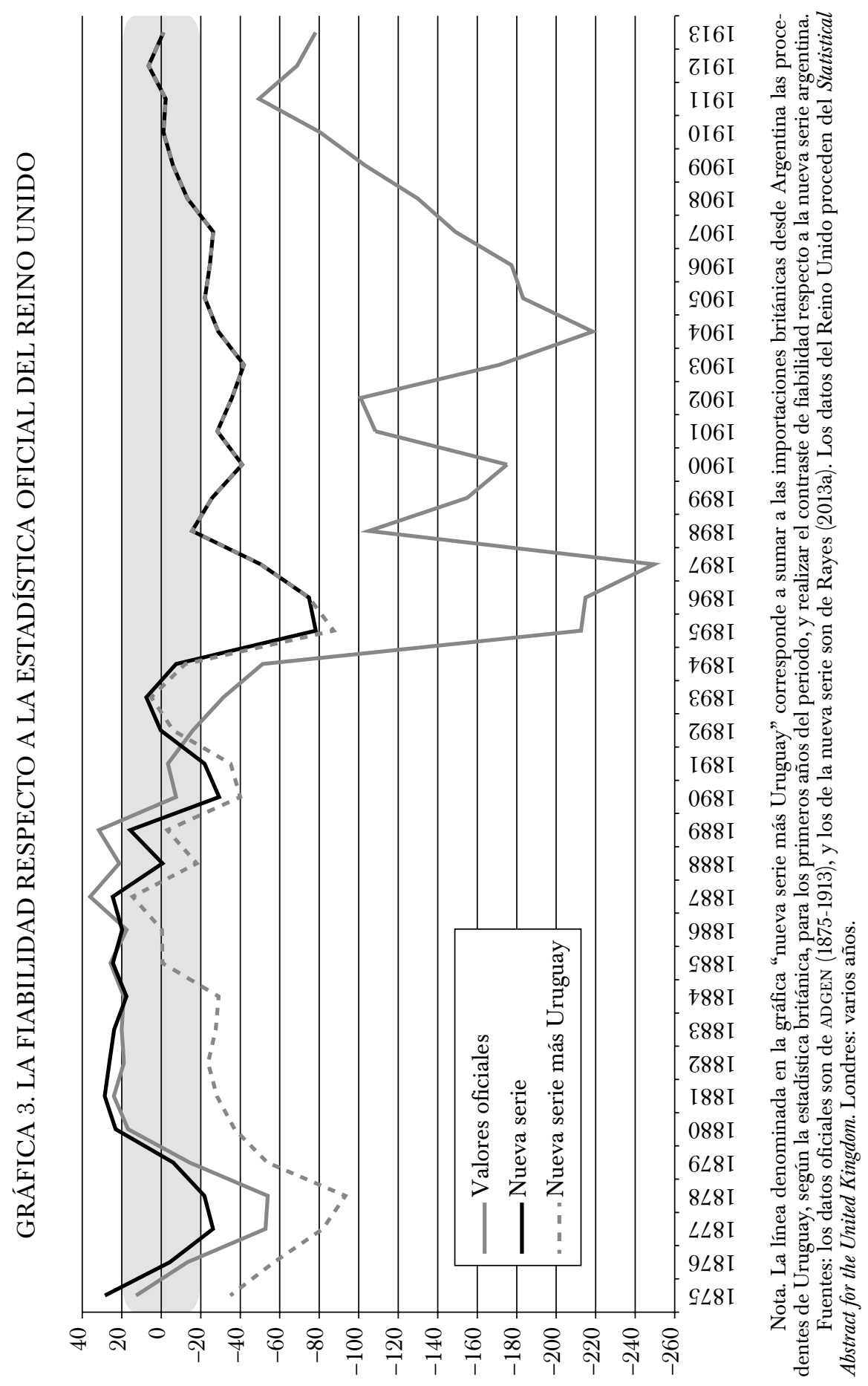


bald (2013). Estos autores estiman que el factor flete osciló en este periodo histórico entre 16 y 28\%, escogiendo $20 \%$ como valor para su corrección.

La banda sombreada en gris indica los márgenes de $20 \%$ en los que las discrepancias entre series podrían justificarse a través de los fletes u otros costes. En los primeros años del periodo se observa un signo inesperado que indica una sobrevaloración argentina o una infravaloración británica. En este último caso, podría tratarse de un problema de asignación geográfica relacionado con el puerto de Montevideo, es decir, la estadística inglesa pudo asignar como uruguaya mercadería que era argentina durante la década de 1880. Platt (1971) subraya la importancia de los problemas asignativos en las estadísticas británicas anteriores a 1900: "Before the improvement of the port of Buenos Aires, late in the nineteenth century, a substantial proportion of Argentine imports was transhipped from ocean steamers at Montevideo, but the new docks reversed the flow, so that Uruguayan imports might now arrive through Buenos Aires" (pp. 119-120). Para poder verificar este punto hemos añadido los datos de las exportaciones uruguayas a la estadística británica en los primeros años del periodo 1875-1893. Ello mejora sustancialmente el problema de la sobrevaloración, lo que indica que una parte importante de esta discrepancia podría, efectivamente, ser atribuida al error asignativo en la estadística británica. Este resultado reafirma el obtenido por Carreras-Marín y Badía-Miró (2008), según el cual las estadísticas latinoamericanas tendrían niveles razonables de fiabilidad en cuanto a la distribución geográfica de su comercio, mientras que las estadísticas europeas adolecerían de sistemáticos sesgos en la asignación geográfica tendentes a sobredimensionar los principales puertos de las rutas transoceánicas.

Una interpretación alternativa se encuentra en el trabajo de Tena y Willebald (2013), autores que también reflejan una sobrevaloración al contrastar su serie corregida con la británica en estos primeros años. En este caso, la explicación se atribuye a una sobrevaloración argentina excepcional debido a la crisis Baring y su efecto depresor de los precios, que no habría sido recogido en los valores oficiales argentinos. Esta explicación podría mantenerse para explicar el moderado repunte de la sobrevaloración a partir de 1890, pero no parece servir para explicar las discrepancias registradas en el periodo anterior.

Desde 1894, el problema del signo positivo desaparece y ambas series presentan el signo esperado, potencialmente explicadas a través de los precios CIF. En esta segunda parte de la gráfica, la serie corregida resulta claramente más aceptable, al separarse menos de la serie británica y mantener un comportamiento relativamente más estable, en comparación con la serie oficial argentina. Aunque ambas series mejoran su fiabilidad desde la década de 1890 hasta el preludio de la primera guerra mundial, la nueva serie se sitúa en márgenes marcadamente mejores a los de la serie oficial. 
Este resultado ilustra con claridad el problema que puede representar el uso de las fuentes oficiales de comercio exterior de Argentina, sin aplicar las correcciones necesarias para el análisis de la distribución geográfica del mismo. En ese caso, se subestimaría la participación del Reino Unido como destino para la exportación argentina. Mientras la serie corregida asigna a este país un peso medio de $22.6 \%$ (con una desviación estándar de 10.6), la serie oficial lo sitúa en $15.7 \%$ (con una desviación estándar de $5 \%$ ), en todo el periodo.

La evolución de la exportación argentina a Francia es el espejo de la británica. Si bien al inicio del periodo las exportaciones con destino francés eran más importantes, siguiendo una clara tendencia creciente hasta principios de los ochenta, a partir de ese momento los mercados galos perdieron importancia en las exportaciones argentinas, a la par que aumentaba la importancia de los mercados británicos. De un máximo de $36 \%$ en 1887, Francia pasó a representar menos de 8\% en 1913.

El cálculo del índice de Morgenstern (1963) es expresado como porcentaje para el caso francés en la gráfica 4 . El signo de las discrepancias es negativo para todos los años, lo cual se enmarca dentro de lo esperable, debido al efecto de los precios CIF. En este caso, las diferencias entre la serie oficial y la serie corregida no son tan visibles como en el caso británico. Si bien la nueva serie tiene un comportamiento más estable y más cercano a la serie francesa en la mayor parte de los años, en el periodo entre 1887 y 1894 la serie oficial se sitúa por encima de la nueva. Sin embargo, las dos series presentan mayores porcentajes de discrepancia estadística que en el caso británico para el conjunto del periodo. Ocurre que o ambas infravaloran el comercio con Francia o las importaciones argentinas en los mercados galos son sobrevaloradas. Nuevamente, se pueden encontrar diferentes explicaciones. Si consideramos que el error está en las series argentinas, por una parte, es posible que la participación de Francia en las exportaciones "a órdenes" entre 1901 y 1905 no fuera constante anualmente, con lo que no quedaría registrado en la extrapolación.

De forma similar a lo que hemos constatado en el caso británico, el problema también puede existir en que la estadística francesa considerara como procedentes de Argentina artículos uruguayos o brasileños; de hecho, tal y como se refleja en otro trabajo (Rayes, 2013a), la estadística francesa incluía como procedentes del "Río de La Plata" distintas partidas de cueros y lanas. Para el caso del comercio bilateral entre Argentina y Francia, el uso de las fuentes oficiales o el de la nueva serie argentina no alcanzan los niveles mínimos de fiabilidad estadística, situándose demasiado por debajo de los límites máximos razonablemente previstos. No obstante, no por ello debiera descartarse, porque el problema puede residir, como señalamos, en el registro estadístico francés. 


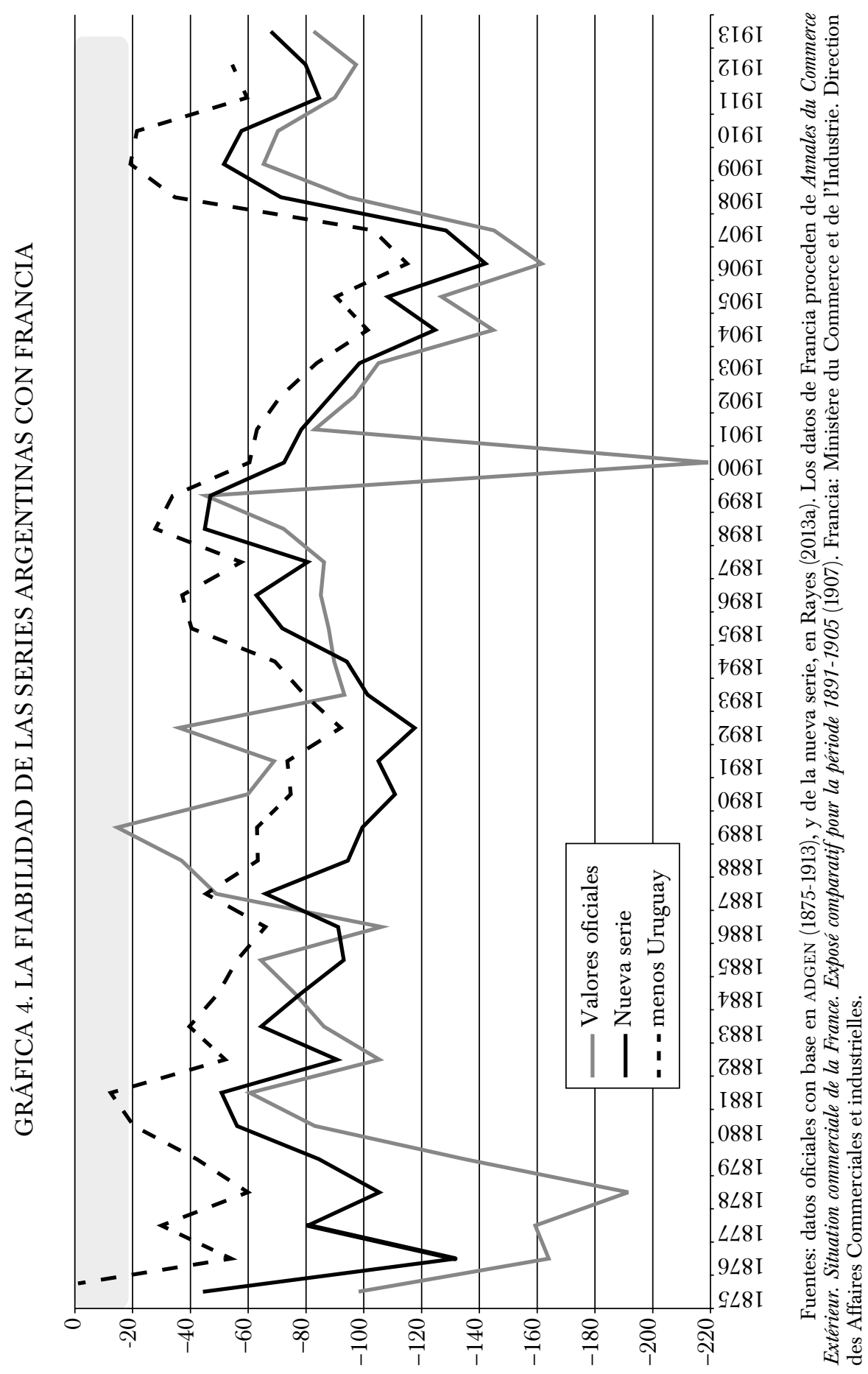


Bajo el supuesto de que el error asignativo se encontrase en la estadística europea, hemos mostrado una segunda línea en la gráfica 4 donde se restan las importaciones desde Uruguay y se realiza el contraste de fiabilidad con la nueva serie. Esta hipótesis mejora la fiabilidad de la estadística argentina en todo el periodo, aunque todavía se encuentra por debajo de las bandas de $20 \%$. Esto podría indicar que los errores asignativos fuesen más complejos que lo que aquí se ha planteado incluyendo a terceros países, como por ejemplo Brasil. A pesar de ello la nueva serie representa una mejora en términos de fiabilidad respecto a la serie oficial argentina. La nueva serie arroja una participación media de Francia en las exportaciones argentinas de $20.1 \%$ (con una desviación estándar de 7.3), muy similar a la serie oficial con una media de 20.3\% (desviación estándar de 7.8).

Bélgica tiene una evolución similar a la de Francia sobre la exportación argentina. Al partir de valores ligeramente por encima de $30 \%$, su tendencia decreció a lo largo de los años y hacia 1913 el mercado belga representaba $8.4 \%$ del valor total exportado. La gráfica 5 muestra los índices de Morgenstern (1963) para la exportación argentina con Bélgica. Durante esta época, el resultado de la nueva serie mejora poco a poco el obtenido con la serie oficial, y más concretamente desde mediados de la década de 1890 por la corrección de los embarques "a órdenes". Para el periodo anterior a este año ambas series muestran una sobrevaloración similar a la que se encontraba en el caso británico. Bajo la hipótesis de que la estadística belga adoleciese de un problema de asignación geográfica, se ha graficado una tercera línea sumando las exportaciones uruguayas. Esta corrección traslada la serie hacia las bandas de fiabilidad de $20 \%$. A pesar de ello persiste una sobrevaloración. En términos generales la nueva serie presenta mejoras evidentes de fiabilidad. Esta atribuye una participación media de Bélgica en las exportaciones argentinas de 15.5\% (con una desviación estándar de 6.4), mientras que la serie oficial la sitúa en $14.9 \%$ (con una desviación estándar de 7.3).

Alemania tuvo una creciente participación en las exportaciones argentinas, de forma similar al caso británico. Al partir de porcentajes muy reducidos, de 2.3\%, tendencia que la situaba por detrás de España o Italia al principio del periodo, alcanzó $20 \%$ a finales de este, superando a Francia, aunque a distancia considerable de los británicos (véase gráfica 6). Antes de 1889 las estadísticas alemanas presentan de forma agregada a Argentina y a Uruguay, con lo que no es posible hacer el contraste bilateral. La serie corregida presenta un resultado claramente mejor que la serie de datos oficiales, excepto en los primeros años, ya que se sitúa en márgenes de $20 \%$ casi todos los años. En contraposición, la serie oficial alcanza porcentajes superiores a 100\% hacia el final del periodo considerado. El principal motivo por el que la nueva serie es más fiable radica 


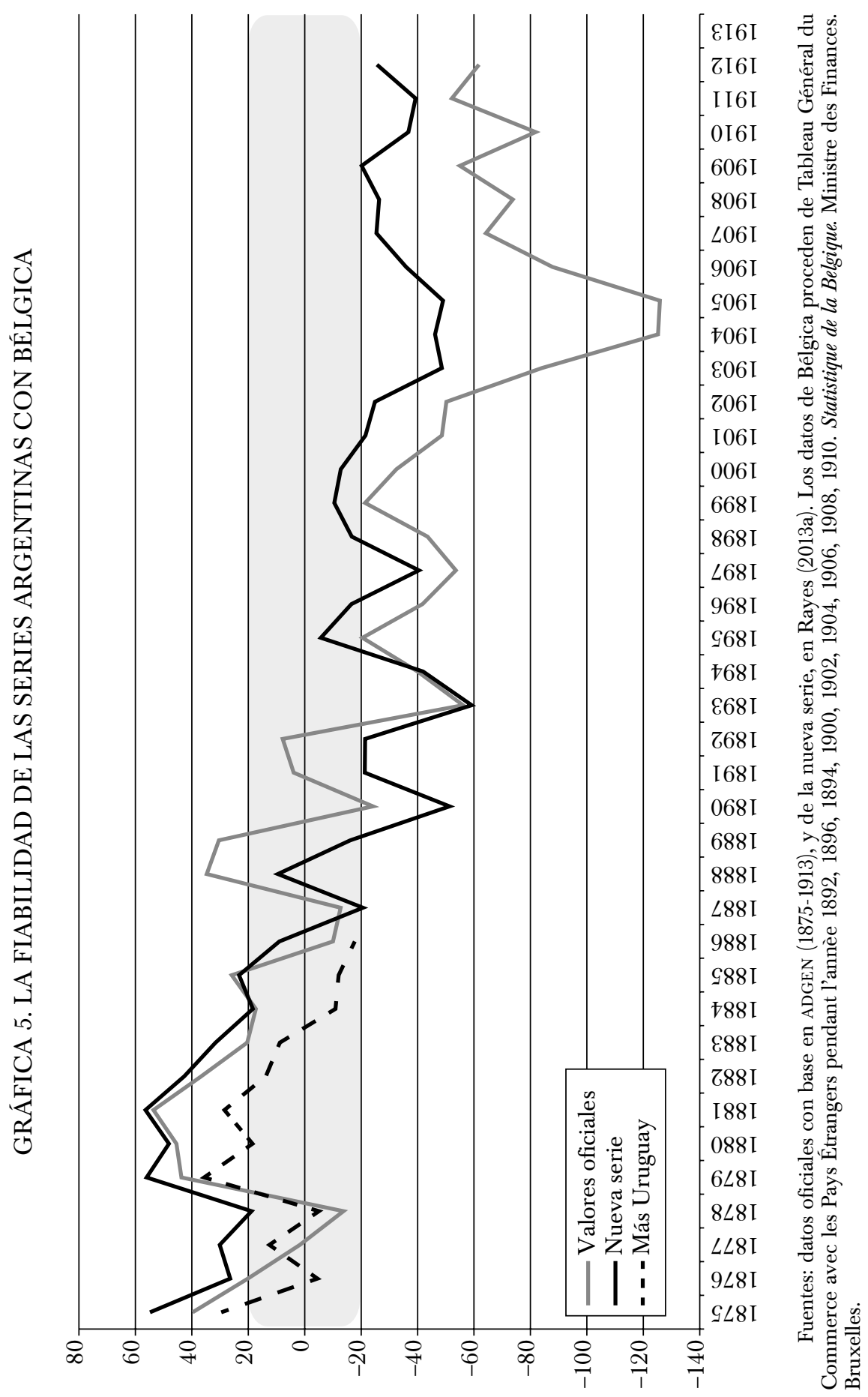




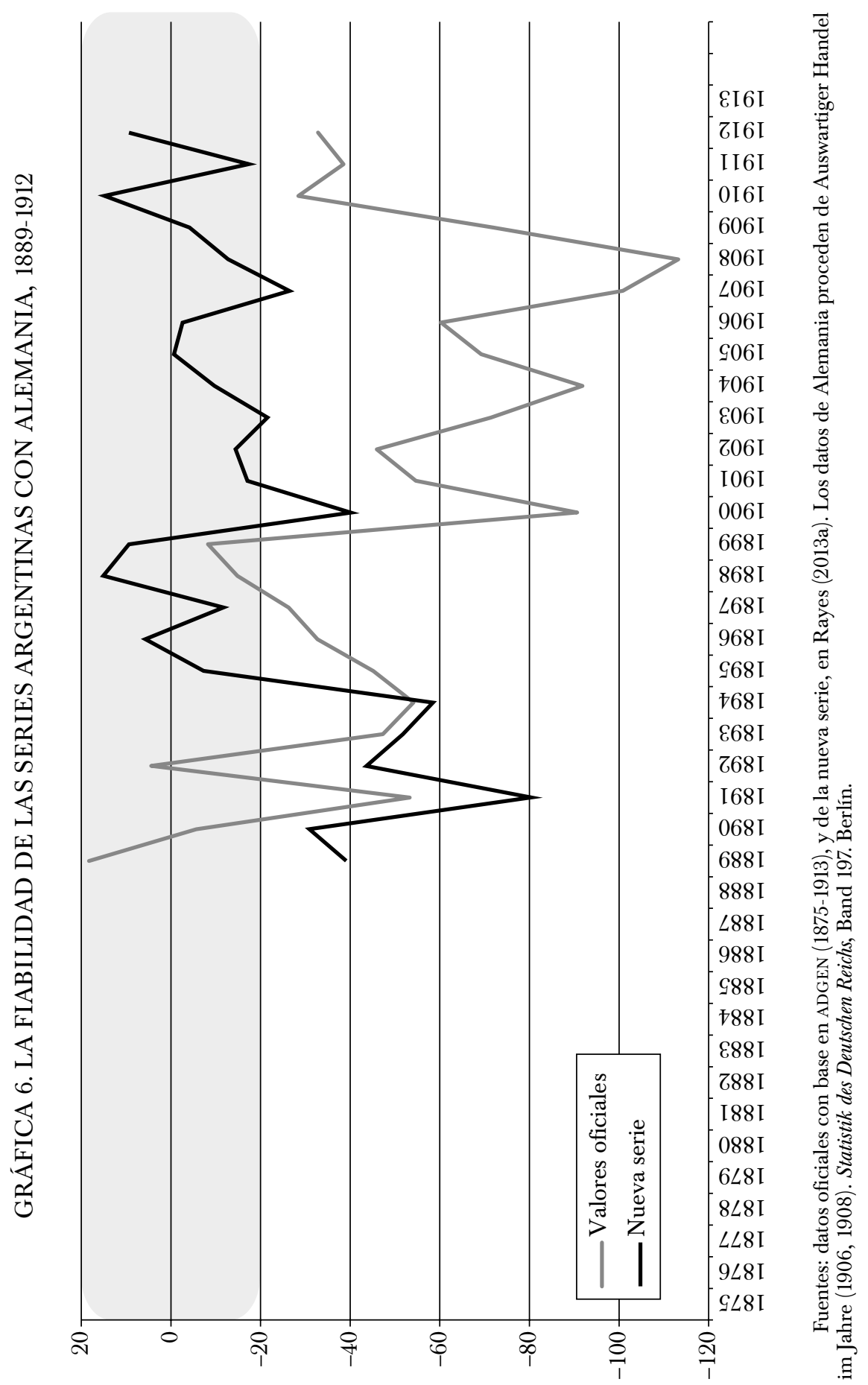


en la asignación de los embarques "a órdenes", ya que Alemania fue una importante compradora de los granos que se enviaban con esa modalidad. Este caso es ilustrativo para subrayar que la diferencia en el uso de una u otra de las series argentinas puede conducir a análisis muy distintos sobre el comercio bilateral. La nueva serie presenta una participación media de Alemania de $12.4 \%$ (desviación estándar de 5.2), mientras que la serie oficial lo hace en 10.4\% (desviación estándar de 3.7).

A continuación, se revisa la fiabilidad de las estadísticas con socios menores en el comercio de exportación argentino. España tenía un peso muy marginal, situándose durante todo el periodo por debajo de $3.8 \%$ del valor total exportado. Si bien en los primeros años se observan algunos episodios de creciente importancia, a partir de la década de 1890 la tendencia es claramente decreciente. España representó para Argentina en promedio 1.5\% de su exportación. En este caso, las cifras oficiales y las de la nueva serie no arrojan resultados diferentes.

Hay que considerar que los porcentajes de las discrepancias estadísticas entre España y Argentina se refieren a valores menores en términos relativos, así que aunque estos sean elevados, los montos totales distan considerablemente de los valores del comercio británico, francés, belga o alemán (véase gráfica 7). En la última década del periodo se observa una agravación de las discrepancias que afecta tanto a la nueva serie como a la oficial. Si lo dejáramos así el resultado sería claramente negativo para la estadística argentina, con o sin correcciones. No obstante, cabe destacar que las series oficiales españolas han sido objeto de serias críticas y, por ello, se han reestimado a partir de la información de los principales socios comerciales (Prados de la Escosura, 1986).

El problema detectado en los valores oficiales registrados por España consistía en una sistemática y persistente sobrevaloración de las importaciones, lo que explicaría la magnitud de las discrepancias negativas desde 1891, año en que se incrementó el arancel proteccionista. Prados de la Escosura (1986) calcula que el porcentaje medio de sobrevaloración de la estadística española entre 1850 y 1913 sería de $27.6 \%$ para los productos primarios (50.6\% en el caso de las manufacturas).

El año 1891 es un punto de inflexión en la serie española, debido al aumento arancelario más la tendencia a la depreciación de la peseta y la deflación. Teniendo en cuenta las correcciones de Prados de la Escosura (1986) para los productos primarios hemos corregido la serie de las importaciones españolas de productos argentinos (véase gráfica 8). En este caso, las discrepancias son totalmente irrelevantes, constatándose una fiabilidad casi perfecta de la estadística argentina. El caso español ilustra con claridad el argumento que pone de relieve que los problemas de fiabilidad de las estadísticas de América Latina se encontraban en muchas ocasiones en el lado europeo. 


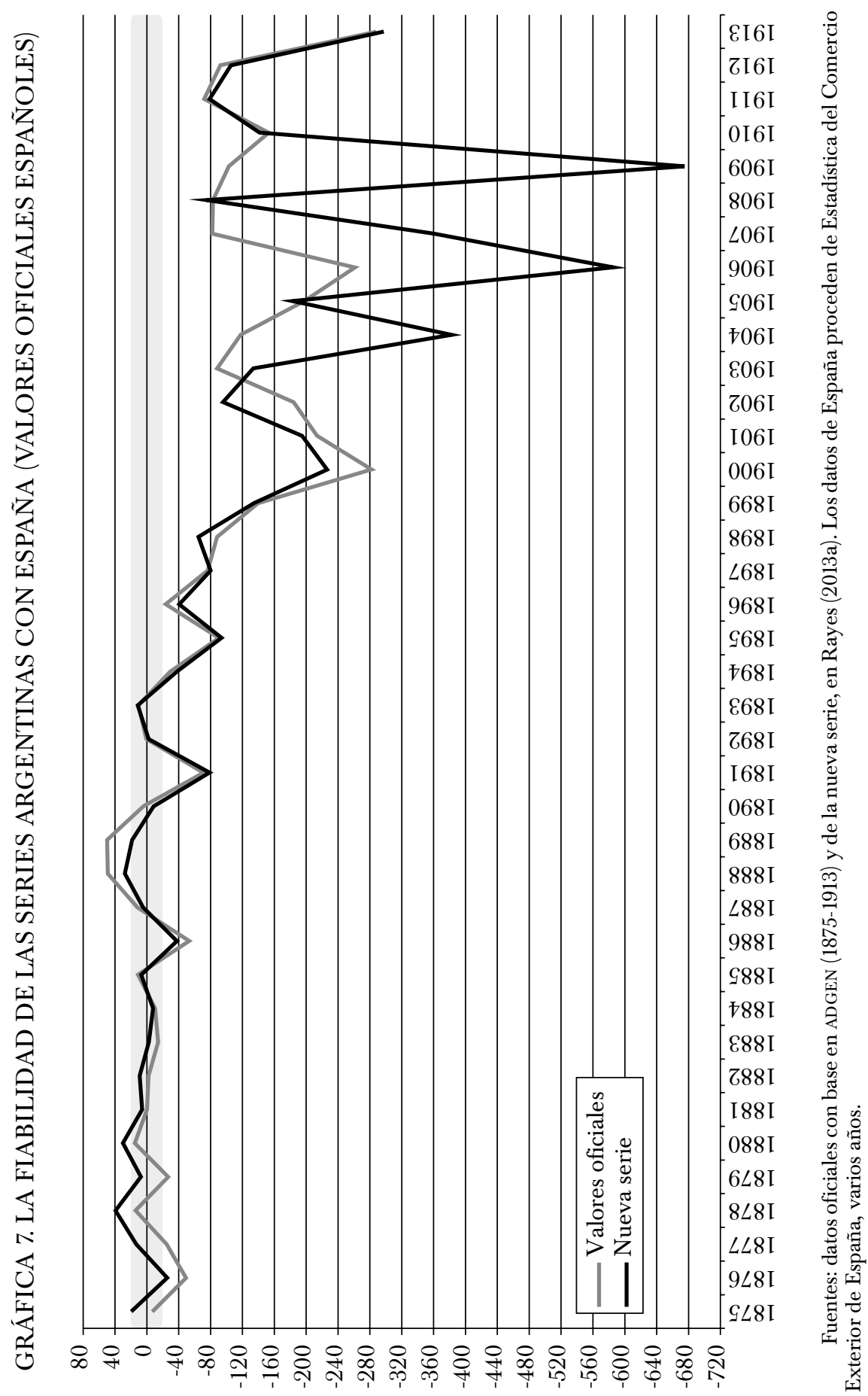




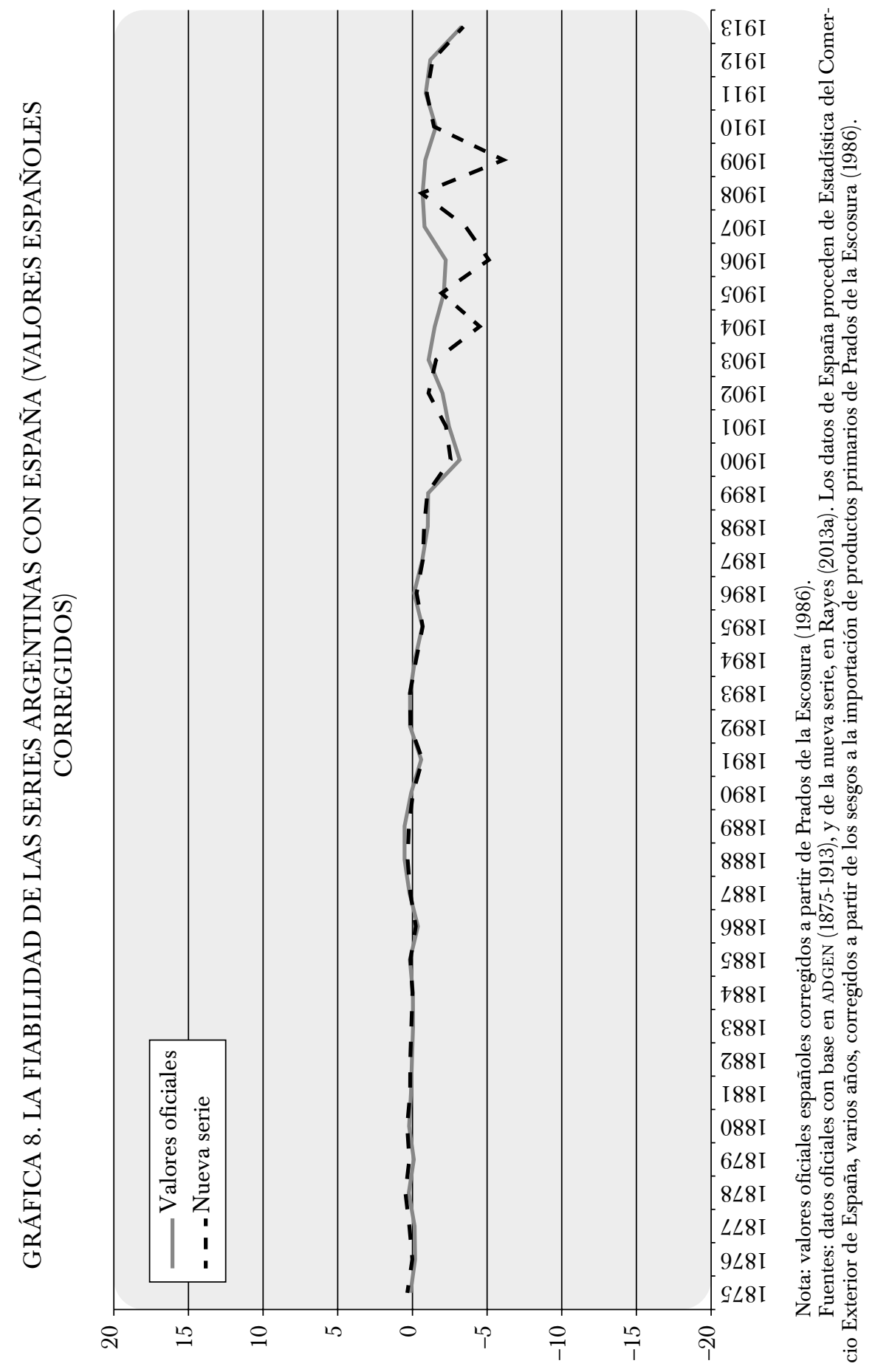


Italia también era un mercado marginal para Argentina, aunque más importante que el español, representando entre 1.5 y $4.6 \%$ de la exportación total argentina. En este caso, sólo se dispone de datos para 1890-1912. La coincidencia entre la serie oficial y la nueva es casi completa para este país, lo cual se explica porque el problema de valoración no es tan grave a partir de mediados de la década de 1890, e Italia no fue un destino sobresaliente de los embarques "a órdenes" (véase gráfica 9). El rango de variación de las discrepancias estadísticas se sitúa siempre dentro de 90\%, situándose fuera de los márgenes de fiabilidad especialmente en la parte final del periodo. La infravaloración argentina podría explicarse por la escasa importancia de los puertos italianos como destinos finales de las embarcaciones salidas desde Sudamérica y la consiguiente llegada de los productos argentinos reexportados desde otras plazas europeas. Sin embargo, de forma similar al caso español, podríamos estar frente a un problema de la estadística italiana. No disponemos de la información necesaria para testear esta segunda hipótesis, lo que queda pendiente para ulteriores investigaciones.

El caso brasileño es similar al italiano en los ciclos de crecimiento y decrecimiento, aunque su importancia para la exportación argentina se sitúa claramente por encima, oscilando entre 2.1 y $13.5 \%$. En este sentido, destaca el incremento en la participación relativa durante el primer quinquenio de la década de 1890, cuando casi alcanzó a cubrir $14 \%$ del valor total exportado, permaneciendo el resto de los años en alrededor de 4 por ciento.

Para el caso de Brasil, sólo se dispone de datos en el periodo 1901-1913 (véase gráfica 10). Las distancias entre la serie oficial y la nueva no son demasiado relevantes y ambas se mantienen en bandas más que razonablemente aceptables, por debajo de $20 \%$ en la mayor parte del periodo. La proximidad geográfica y la ausencia del comercio "a órdenes" probablemente sea la explicación de la menor incidencia de los errores asignativos entre sus estadísticas. El resultado razonablemente fiable de los datos de comercio con Brasil refuerza la hipótesis de que frecuentemente los problemas de fiabilidad se derivan de errores de asignación geográfica con los socios comerciales geográficamente más distantes.

Estados Unidos es el último socio comercial de nuestra muestra de países. Este país representó entre 3.4 y 10.4\% de las exportaciones argentinas, una participación similar a la que tenía Brasil (véase gráfica 11). Aunque en los primeros años las bandas de $20 \%$ se superan, en la mayor parte del periodo ambas series se sitúan en niveles razonablemente aceptables de fiabilidad estadística. La nueva serie otorga a Estados Unidos una participación media de 6\% (desviación estándar de 1.8), mientras que la serie oficial lo hace en $5.7 \%$ (desviación estándar de 1.4). Las diferencias en este caso no son muy significativas. 


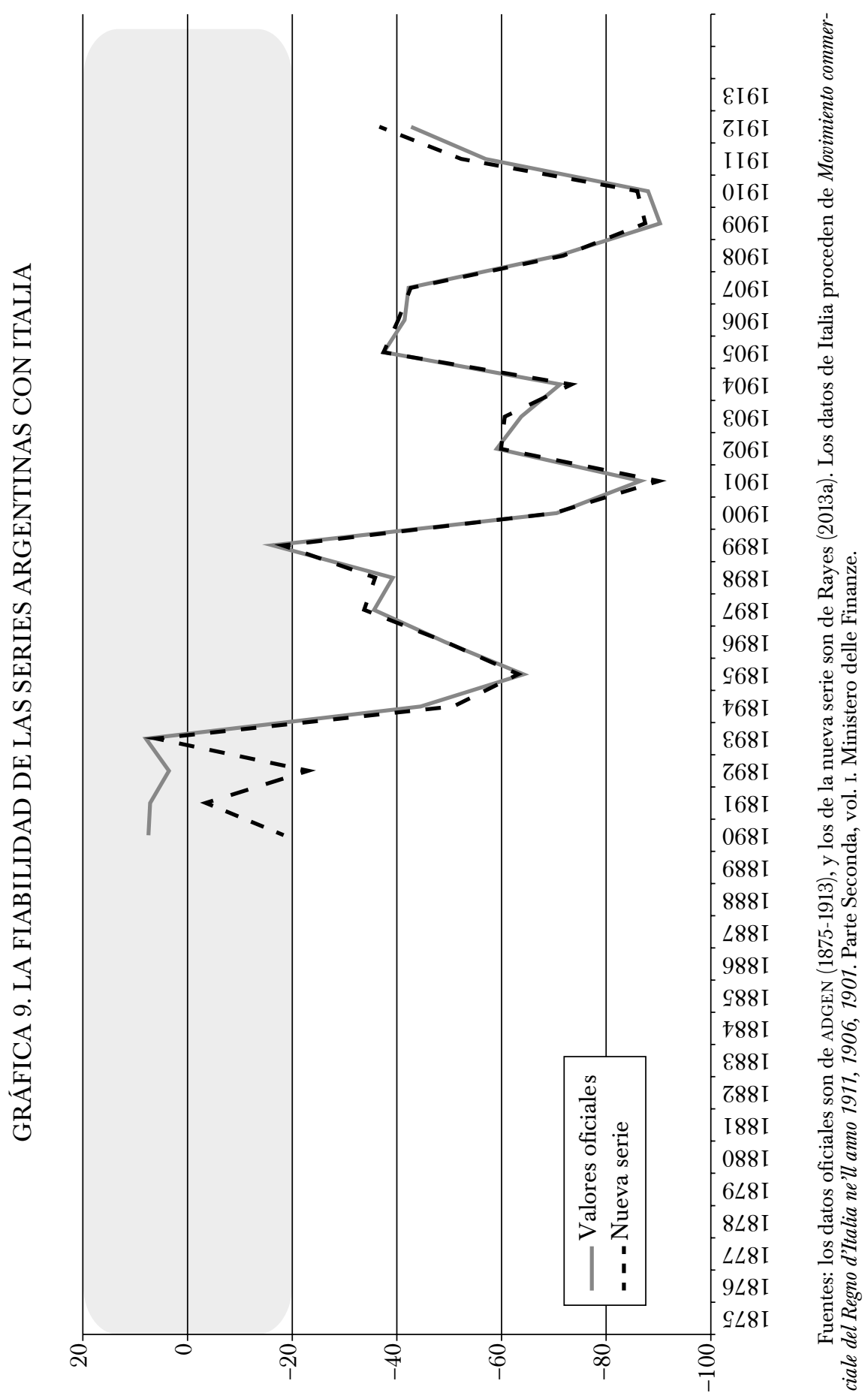




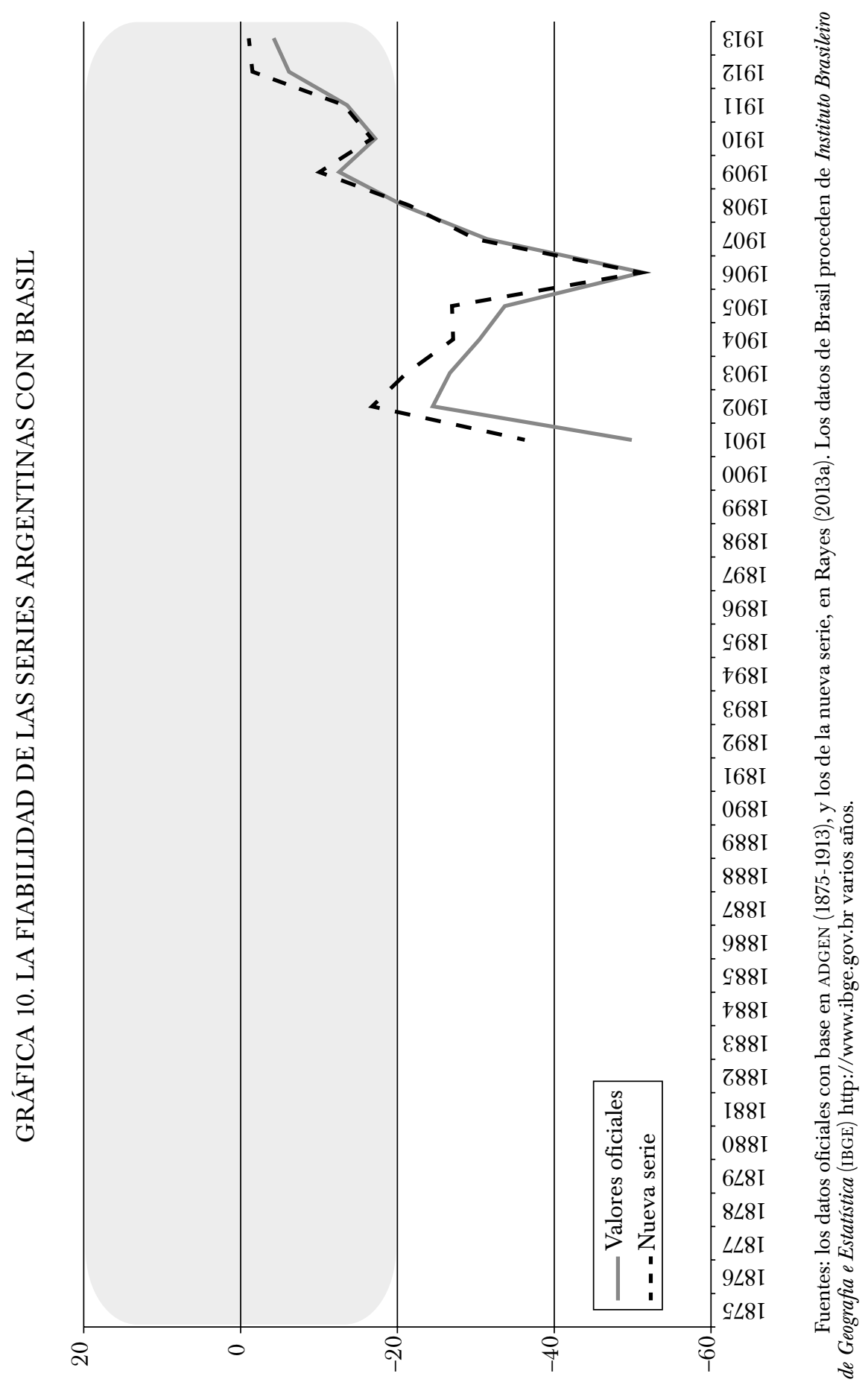




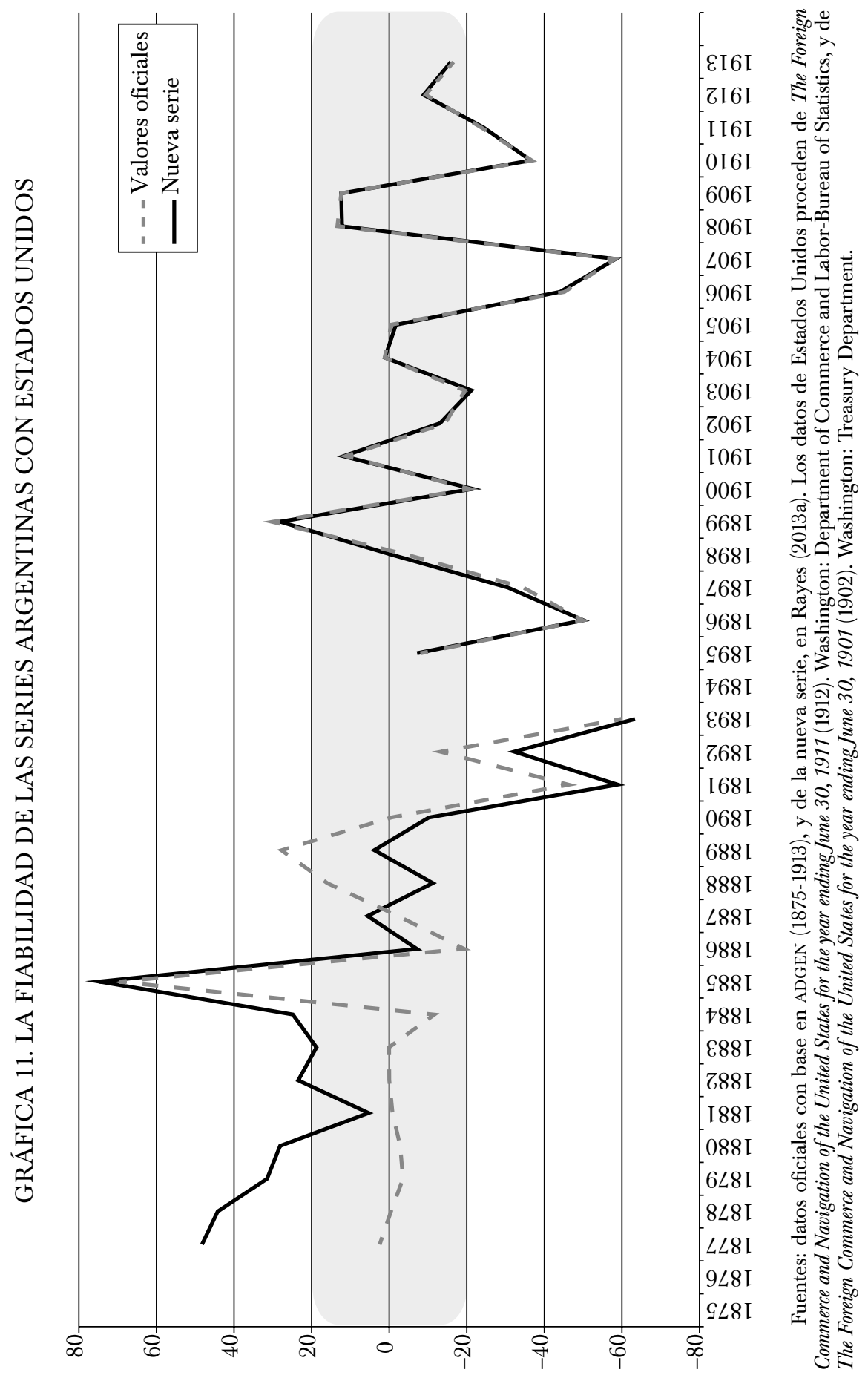




\section{LA FIABILIDAD DE LAS ESTADÍSTICAS ARGENTINAS A PARTIR DE LA AGREGACIÓN GEOGRÁFICA}

En el apartado anterior se ha analizado la fiabilidad de las estadísticas argentinas de forma bilateral con ocho de sus socios comerciales. Los resultados han sido diversos aunque en general la nueva serie aparece más próxima a los valores de los socios comerciales. A continuación se desarrolla un análisis conjunto de la fiabilidad de las series, agregando los resultados para los países considerados. Para ello, se aplica el índice de Federico y Tena (1991), aunque parcialmente limitado a la muestra de países disponibles. Cabe señalar que este indicador permite reducir los márgenes de las discrepancias estadísticas entre socios comerciales a partir de la neutralización de los errores de asignación. En algunos de los países analizados anteriormente el error de asignación ha aparecido como una posible causa explicativa de las discrepancias entre socios comerciales y se han corregido los posibles sesgos geográficos de los socios comerciales cuando dicha información se encontraba disponible. En este nuevo contraste, se aborda el posible error asignativo de la estadística argentina. Ello es importante ya que la principal corrección de la nueva serie pretende superar dichos problemas. Sin embargo, el hecho de no incluir todos los socios comerciales de Argentina en este análisis determina que esta neutralización resulte limitada geográficamente a la muestra (véase gráfica 12).

La impresión obtenida en el análisis de país a país aparece confirmada en la agregación, siendo el caso francés el que sitúa la nueva serie por debajo de las bandas de $20 \%$ en parte del periodo analizado. A pesar de que los resultados podrían mejorarse con un análisis pormenorizado de la asignación geográfica de la estadística francesa, la serie corregida presenta menores fluctuaciones y se mantiene en márgenes razonables de discrepancia estadística con sus socios comerciales, con una clara mejoría en los últimos años del periodo. En contraposición, la serie oficial presenta fluctuaciones excesivamente amplias y alcanza niveles de discrepancia que no pueden explicarse de forma razonable, alcanzando valores más allá de $90 \%$. Ello confirma el principal resultado de Tena y Willebald (2013) en relación con la subvaloración de los datos oficiales de la exportación argentina en términos generales, hipótesis planteada previamente por Cortés, Halperin y Gorostegui de Torres (1965) y Díaz (1983). Nuestra principal aportación consiste en que la nueva serie revela niveles de mayor precisión estadística en relación con los valores oficiales, por un lado, y que en los primeros años los errores asignativos se encontrarían en ambos lados del intercambio comercial, siendo especialmente relevantes en el caso de las estadísticas europeas. 


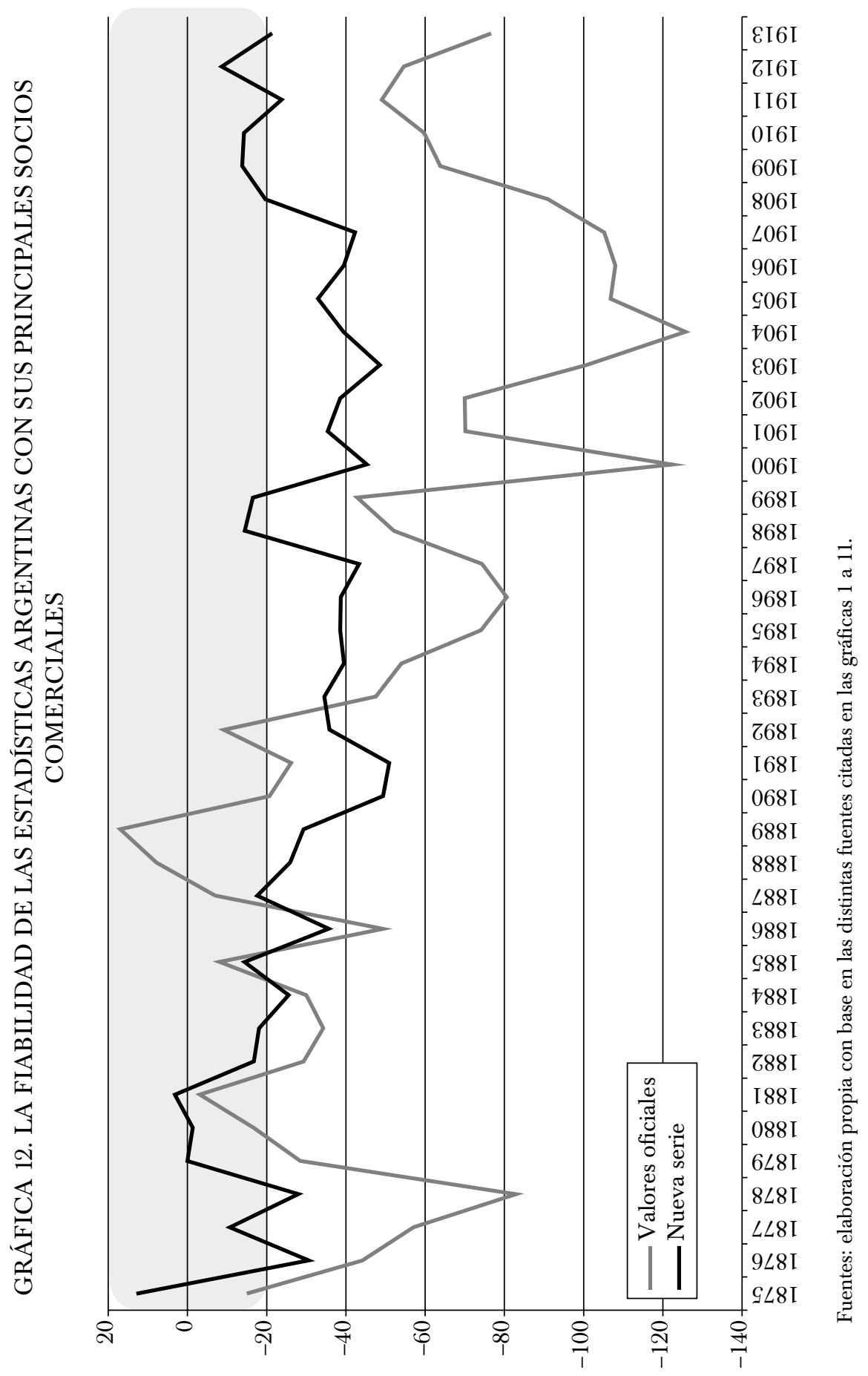




\section{LA DISTRIBUCIÓN GEOGRÁFICA DE LA EXPORTACIÓN ARGENTINA}

El cuadro 1 compara los resultados en términos de distribución geográfica de las tres series de exportación argentina disponibles: nuestra nueva serie (NS), la serie oficial (OF) y la serie de Tena y Willebald (TW). Los datos se presentan como medias quinquenales para homogenizar los porcentajes respecto a la serie de Tena y Willebald (2013). En el caso de Gran Bretaña las diferencias aparecen a partir de 1890, cuando la NS se distancia mostrando una creciente participación relativa de las plazas británicas en las exportaciones argentinas, mientras que las otras dos exhiben porcentajes muy similares. En 1890-1894 la NS sitúa a Gran Bretaña cinco puntos por encima de la OF, en 1895-1899 lo hace en nueve, en 1900-1904 en doce, en 1905-1909 en 17 y en 1910-1913 en quince. Algo similar ocurre con Alemania, donde la diferencia se advierte a partir de 1895. En el caso alemán la NS sitúa a este país dos puntos por encima de la OF en 1895-1899 y en los sucesivos periodos lo hace en cinco, siete y cuatro puntos, respectivamente. Con Bélgica las diferencias se producen al final del periodo. En 1905-1909 la NS pone a Bélgica tres puntos por delante, mientras que en 1910-1913 lo hace en dos. Ni España, ni Italia, ni Brasil experimentan cambios relevantes en las tres series de datos.

Si bien en la mayor parte de la muestra de países la serie de TW se comporta igual que la OF, no lo hace en el caso francés ni en el caso de Estados Unidos. La participación relativa de Francia como destino de la NS es muy parecida a la de TW y diferente de la OF desde 1880 en la siguiente magnitud: catorce puntos (1880-1884), 17 (1885-1889), doce (1890-1894), trece (1895-1899), once (1900-1904), cinco (1905-1909) y siete (1910-1913). La NS ubica a Estados Unidos dos puntos por encima de las otras dos series en 1875-1879, pero para el resto de los años las diferencias son de uno como máximo. La de TW es la que más se aparta de las otras en este caso, aunque sólo en algunos periodos de tiempo: tres puntos por debajo en $1890-1894$ y en $1900-1904$.

\section{CONCLUSiOnes}

Mucho se ha escrito sobre el papel de las exportaciones en el crecimiento económico de América Latina durante la primera globalización. Sin embargo, menos se ha discutido y mejorado el material estadístico para recrear las condiciones económicas de la época. En otros estudios hemos trabajado sobre los factores de crecimiento de las exportaciones argentinas de acuerdo con la evidencia empírica reconstruida (por ejemplo, Míguez y Rayes, 2014, Rayes 2013a,). El estudio aquí expuesto apunta a 


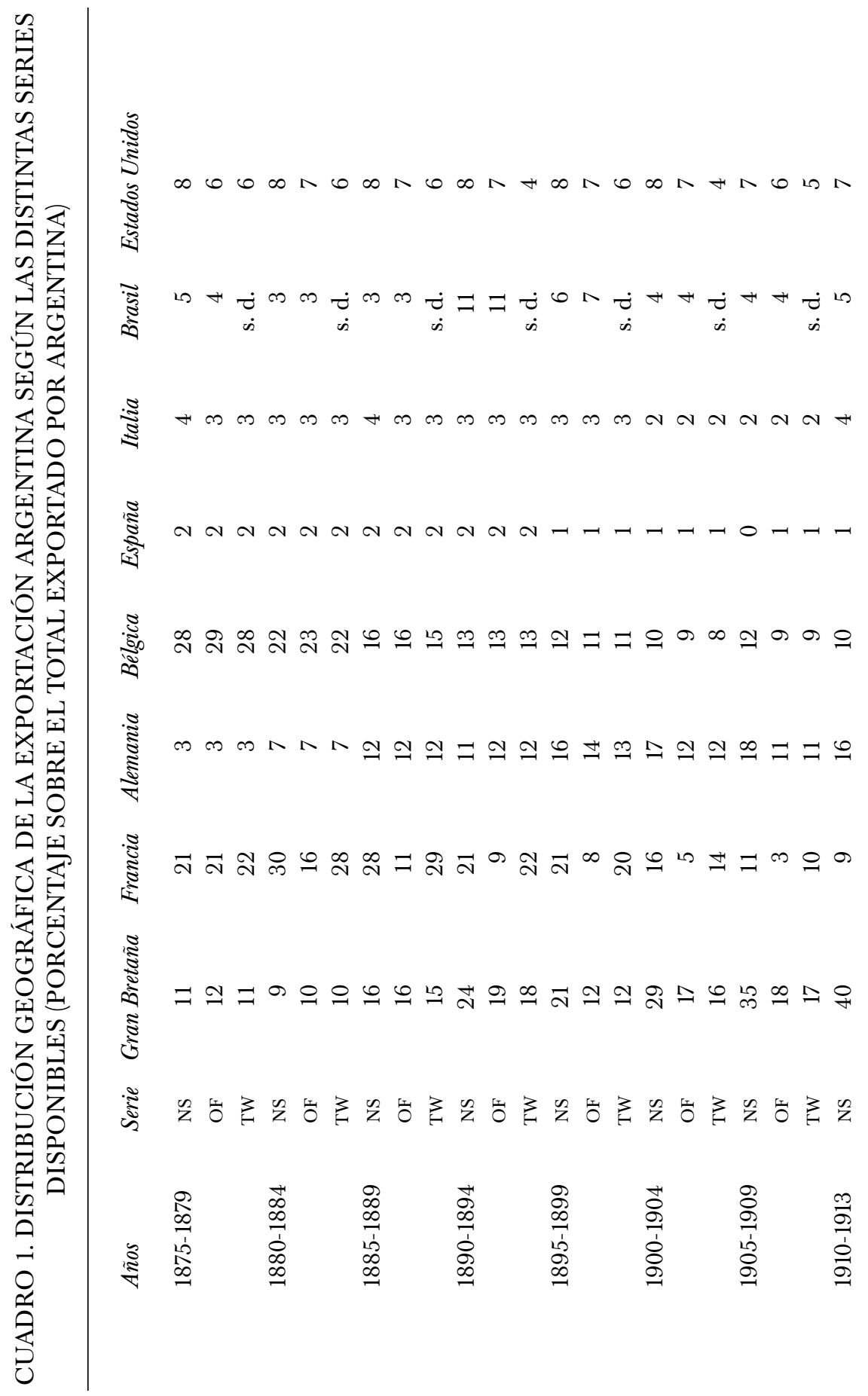




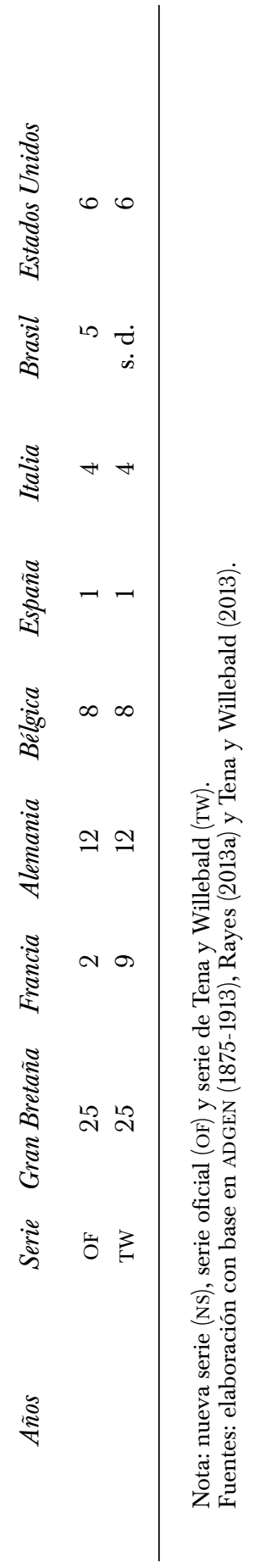


evaluar los alcances y limitaciones de la serie oficial de comercio exterior y de las nuevas series aparecidas recientemente -corregidas en términos de precios y de asignación geográfica- para el caso argentino entre 1875 y 1913. El trabajo se ha realizado a partir del análisis de la fiabilidad de las estadísticas de exportación argentinas en comparación con los registros de importación de ocho de sus principales socios comerciales.

En términos generales, el contraste entre series pone de relieve la mayor fiabilidad de la nueva serie en contraposición con los datos oficiales aunque no soluciona absolutamente las diferencias de registros. Si bien el caso francés, así como el italiano son susceptibles de mejora, para el resto de los países se verifican niveles razonables de fiabilidad.

El principal aporte de este análisis ha consistido en explicar la aparente falta de fiabilidad de la estadística argentina a través de los errores asignativos de algunas de las estadísticas europeas. Con ello se sostiene que el hecho de que la nueva serie se sitúe en algunos casos fuera de las bandas de $20 \%$ no necesariamente significa que sea la estadística argentina la responsable, sino que podría deberse a la estadística del socio comercial. En el caso británico ha quedado de manifiesto que la confusión con las importaciones uruguayas ayuda a mejorar la fiabilidad estadística argentina en los primeros años del periodo. Por otro lado, el caso español ejemplifica cómo los problemas de la estadística española una vez corregidos permiten una mejora sustancial de la fiabilidad argentina.

Desde las fuentes de los socios comerciales, la nueva serie dista de las fuentes oficiales que tendieron a subvalorar el comercio con el Reino Unido e introduce transformaciones que revalorizan y mejoran el conocimiento de las exportaciones hacia Alemania, Francia y Bélgica. En cuanto a los partenaires menores, no presenta grandes cambios respecto a la oficial.

En materia de distribución geográfica, las dos series corregidas muestran variaciones considerables en relación con las series oficiales. El caso más destacable es el aumento de la importancia del comercio francés en ambos casos desde 1880 hasta 1913. En cambio, para el caso británico y alemán, nuestra serie arroja porcentajes mayores de los que indica la serie oficial o la de Tena y Willebald. Tales discrepancias se deben a los distintos métodos de corrección, tanto para los precios como para la asignación geográfica.

En síntesis, visto que la nueva evidencia empírica resulta más fiable, especialmente en contraste con los datos oficiales, la misma puede utilizarse para profundizar los debates acerca del crecimiento económico guiado por las exportaciones y la relación entre la concentración geográfica y el desempeño exportador, cuyas conclusiones pueden resultar significativas en vista de que Argentina ha sido considerada para este periodo como el ejemplo paradigmático latinoamericano de export-led-growth. 


\section{LISTA DE REFERENCIAS}

Accominotti, O., Flandreau, M. y Rezzik, R. (2011). The spread of empire: Clio and the measurement of colonial borrowing costs. The Economic History Review, 64, 385-407.

Allen, R. y Ely, J. (1953). International trade statistics. Nueva York.

Álvarez, J. (1929). Temas de historia económica argentina. Buenos Aires: El Ateneo.

Anuarios de la Dirección General de Estadística de la Nación (1875-1913) [ADGEN]. Dirección General de Estadística de la Nación, Buenos Aires.

BÉrtola, L. y GERCHUNOFF, P. (eds.) (2011). Institucionalidad y desarrollo económico en América Latina. Madrid: Comisión Económica para América Latina y el Caribe/ Agencia Española de Cooperación Internacional para el Desarrollo.

Bértola, L. y OCAMPo, J. A. (2013). El desarrollo económico de América Latina desde la independencia. México: Fondo de Cultura Económica.

Bunge, A. (1918). Intercambio económico de la república, 1910-1917. Buenos Aires: Dirección de Estadística.

Carreras, A. y Tafunell, X. (2005). Capital goods imports and investment in Latin America, 1913 and 1925. Economic History Society, Annual Conference (University of Leicester), Academic session: IIIE: Latin American Development.

Carreras-Marín, A. (2005). Geographical effects on the accuracy of textile trade data: An international approach for 1913, Universitat Pompeu Fabra, Barcelona, Economics E Business Working Papers, núm. 821.

Carreras-Marín, A. y Badia-Miró, M. (2008). La fiabilidad de la asignación geográfica en las estadísticas de comercio exterior: América Latina y el Caribe (19081930). Revista de Historia Económica (second series), 26(3), 355-373.

Carreras-Marín, A., Badia-Miró, M. y Peres-Cajías, J. (2013). Intraregional trade in South America, 1912-1950: The cases of Argentina, Bolivia, Brazil, Chile and Peru. Economic History of Developing Regions, 28(2), 1-26.

CORTÉs, R. (1974). Hispanoamérica: la apertura del comercio mundial, 1850-1930. Buenos Aires: Paidós.

Cortés, R., Halperin, T. y Gorostegui de Torres, H. (1965). Evolución del comercio exterior argentino: vol. I. Exportaciones. Buenos Aires: Universidad Torcuato Di Tella.

DíAz, C. F. (1983). Ensayos sobre la historia económica argentina. Buenos Aires: Amorrortu.

DiéGuEz, H. L. (1972). Crecimiento e inestabilidad del valor y el volumen físico de las exportaciones argentinas en el periodo 1864-1963. Desarrollo Económico, 12(46), 333-349.

FEDERICO, G. y TenA A. (1991). On the accuracy of foreign trade statistics (1909-1935): Morgernstern revisited. Explorations in Economic History, 28, 259-273.

FERreres, O. (dir.) (2010). Dos siglos de economía argentina (1810-2010). Historia argentina en cifras. Buenos Aires: El Ateneo.

Gerchunoff, P. y LlaCh, L. (2007). El ciclo de la ilusión y el desencanto. Un siglo de políticas económicas argentinas. Buenos Aires: Emecé Editores. 
Kuntz, S. (2002). Nuevas series del comercio exterior de México, 1870-1929. Revista de Historia Económica, 20(2), 213-270.

LATZINA, F. (1905). Estadística retrospectiva del comercio exterior argentino 1875-1904. Buenos Aires: Compañía Sud Americana de Billetes de Banco.

Míguez, E. (2008). Historia económica de la Argentina. De la conquista a la crisis de 1930. Buenos Aires: Editorial Sudamericana.

Míguez, E. y Rayes, A. (2014). La naturaleza de la dependencia, la dependencia de la naturaleza. Las exportaciones argentinas 1890-1938 en perspectiva comparada. Desarrollo Económico, 211(53), 313-344.

Mitchell, B. R. (1998). International historical statistics. The Americas, 1750-1993. Londres: Macmillan.

Morgernstern, O. (1963). On the accuracy of economic observations. Nueva Jersey: Princeton University Press.

Organización Mundial del Comercio [OMC] (2011). Estadísticas del comercio internacional. Ginebra: OMC. Recuperado de http://www.wto.org/spanish/res_s/ statis_s/its2011_s/its11_metadata_s.pdf

PlatT, D. C. M. (1971). Problems in the interpretation of foreign trade statistics before 1914. Journal of Latin American Studies, 3(2), 119-130.

Prados de la Escosura, L. (1986). Una serie anual del comercio exterior español (1821-1913). Revista de Historia Económica-Journal of Iberian and Latin American Economic History, 4(1), 103-150.

Rapoport, M. (2013). Historia económica, política y social de la Argentina (1880-2003). Buenos Aires: Macchi.

RAYES, A. (2013a). En las puertas del Dorado. Las exportaciones argentinas, 1890-1913 (Tesis de doctorado en Historia). Universidad Torcuato Di Tella, Buenos Aires.

RAYES, A. (2013b). "Bestias negras de la estadística". Las exportaciones argentinas "a órdenes”, 1895-1913. Estadística e Sociedade, 3, 6-20.

RAYES, A. (2015a). El crecimiento de las exportaciones argentinas durante la primera globalización, 1875-1913. Investigaciones y Ensayos, 61.

RAYES, A. (2015b). La estadística de las exportaciones argentinas, 1875-1913. Nuevas evidencias e interpretaciones. Investigaciones de Historia Económica, 11, 31-42.

Rubio, M. y Folchi, M. (2005). On the accuracy of Latin American trade statistics: A nonparametric test for 1925. Universitat Pompeu Fabra, Barcelona, Economics $\mathcal{E}$ Business Working Papers, núm. 879.

Sutch, R. y Carter, S. (eds.) (2006). Historical statistics of the United States. Millenial edition (vol. 5). Cambridge: Cambridge University Press.

TEnA, A. (1991). Las estadísticas históricas del comercio internacional (1890-1960): fiabilidad y comparabilidad (Tesis doctoral). Universidad de Alcalá de Henares, Madrid.

TENA, A. (1992). Las estadísticas históricas del comercio internacional: fiabilidad y comparabilidad. Servicio de Estudios. Estudios de Historia Económica. Banco de España, núm. 24. 
Tena, A. y Willebald, H. (2013). On the accuracy of export growth in Argentina, 1870-1913, Economic History of Developing Regions, 28(1), 28-68.

VÁZQuez, V. (1969). Un análisis de las causas del crecimiento y de la diversificación de las exportaciones argentinas antes de la Primera Guerra Mundial. Buenos Aires: EudeBA.

VÁZQUEZ, V. (1971). Estadísticas históricas argentinas (comparadas). Primera parte (18751914). Buenos Aires: Macchi. 